\title{
Multiterminal HVDC System with Power Quality Enhancement
}

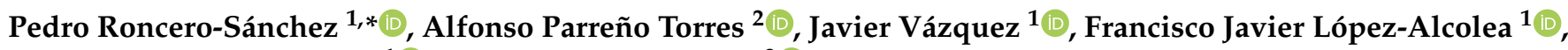 \\ Emilio J. Molina-Martínez ${ }^{1}$ (D) and Felix Garcia-Torres ${ }^{3}$ (D) \\ 1 Institute of Energy Research and Industrial Applications, University of Castilla-La Mancha, \\ Campus Universitario S/N, 13071 Ciudad Real, Spain; Javier.Vazquez@uclm.es (J.V.); \\ FJavier.Lopez@uclm.es (F.J.L.-A.); EmilioJose.Molina@uclm.es (E.J.M.-M.) \\ 2 Institute of Industrial Development, Castilla-La Mancha Science and Technology Park, \\ Paseo de la Innovación 1, 02006 Albacete, Spain; Alfonso.Parreno@pctclm.com \\ 3 Applications Unit, Centro Nacional del Hidrógeno, 13500 Puertollano, Spain; felix.garcia@cnh2.es \\ * Correspondence: Pedro.Roncero@uclm.es
}

Citation: Roncero-Sánchez, P.; Parreño Torres, A.; Vázquez, J.; López-Alcolea, F.J.; Molina-Martínez, E.J.; Garcia-Torres, F. Multiterminal HVDC System with Power Quality Enhancement. Energies 2021, 14, 1306 https://doi.org/10.3390/en14051306

Academic Editor: Mario Marchesoni

Received: 14 January 2021

Accepted: 23 February 2021

Published: 27 February 2021

Publisher's Note: MDPI stays neutral with regard to jurisdictional claims in published maps and institutional affiliations.

Copyright: (c) 2021 by the authors. Licensee MDPI, Basel, Switzerland. This article is an open access article distributed under the terms and conditions of the Creative Commons Attribution (CC BY) license (https:/ / creativecommons.org/licenses/by/ $4.0 /)$.

\begin{abstract}
High-Voltage Direct Current (HVDC) systems are a feasible solution that allows the transmission of energy between several power networks. As a consequence of the use of HVDC systems, renewable energy sources can be integrated more easily into distribution grids and smart grids. Furthermore, HVDC systems can contribute to improving the power quality (PQ) of the grids to which they are connected. This paper presents a multiterminal HVDC system that not only controls the flows of active power between four different networks, but also compensates imbalances and harmonics in the grid currents to maintain balanced and sinusoidal voltages at the point of common coupling of the various grids. The compensation is carried out by the voltage-source converters (VSCs) connected to their respective AC grids. A control scheme based on the use of resonant regulators and proportional-integral (PI) controllers is responsible for of achieving the necessary power flow control with the amelioration of the PQ. A case study of a multiterminal HVDC system that comprises four terminals sharing a DC bus of $80 \mathrm{kV}$ is simulated by means of PSCAD ${ }^{\mathrm{TM}} /$ EMTDC $^{\mathrm{TM}}$ (Power System Computer-Aided Design; Electromagnetic Transients including Direct Current), where the AC grids associated with the terminals suffer from voltage imbalances and voltage harmonics owing to the connection of unbalanced loads and nonlinear loads. The obtained simulation results show the performance of the complete system in terms of active power flow, voltage regulation, and harmonic distortions of the grid current and the grid voltage.
\end{abstract}

Keywords: power quality; multiterminal HVDC system; multilevel voltage-source converter; distribution grids; resonant controller

\section{Introduction}

In recent years, electrical systems for distributed generation have experienced increased expansion and importance owing to the increase in the integration of different renewable energy sources, such as photovoltaics and wind energy. As a consequence, a multidirectional energy flow is present in the point of common coupling (PCC), which is simultaneously shared by loads and generators. Voltage-source converter high-voltage direct current (VSC-HVDC) systems allow us to exploit the feature of a multidirectional power flow, as they can be used to interconnect several AC grids by means of DC networks [1]. Since HVDC systems offer some superior advantages to those of high-voltage alternating current (HVAC) schemes-such as the asynchronous connection of two or more independent AC networks, the lack of reactive power in the DC link, lower power losses [2]-they can contribute to provide a more reliable power network and to the development of smart grids $[3,4]$.

From the first commercial HVDC system, i.e., the HVDC Gotland [5], to the present day, power electronics has undergone great advances. Several commercial HVDC systems 
can be found involving various technologies, such as HVDCs based on current-source converters (CSC), in addition to the current VSC-HVDCs. The main different converter technologies have been explained in [6].

In accordance with [7,8], VSC-HVDC systems exhibit some advantages with regard to CSC-HVDCs, such as their four-quadrant operation, their use in the connection to both strong and weak grids, high dynamic performance and multiterminal possibility, and greater controllability [9]. Furthermore, multilevel topologies for VSC can be used in HVDCs in order to synthesize an output voltage with a low harmonic distortion. The most well-known multilevel configurations are the neutral-point clamped (NPC) converter [10], the flying-capacitor (FC) converter [11], and the modular multilevel converter (MMC) [12].

Among all the flexible transmission systems (FTS), HVDCs are the devices that offer the broadest range of functionalities, such as voltage control, active and reactive power control, frequency control, and the interconnection of AC systems [7]. Besides, HVDCs also feature some power quality (PQ) functionalities in order to ameliorate the PQ of the AC grids to which they are connected [13].

Several works have dealt with some PQ issues related to HVDC systems. In [14], a strategy to extend the operation region of MMC-based HVDCs by means of the current injection of a second harmonic was presented; this second component must be carefully injected in order to obtain proper behavior of the converter. As a result, a wider range of active and reactive powers could be controlled with a sinusoidal current injected by the HVDC into the grid. Nevertheless, this work did not study the compensation of current harmonics caused by loads connected to AC networks. A proposal to improve the PQ using multiterminal VSC-HVDC systems was presented in [15], where a total solution to the PQ issue was described. Nonetheless, the control structure was reduced to the use of conventional proportional-integral (PI) regulators to achieve decoupled control of the active and reactive powers, while the use of passive high-pass filters was proposed to reduce the output voltage distortion of the VSC-HVDC, which is an expensive solution. On the other hand, the use of a modified active filter to improve the PQ in a HVDC link was proposed in [16]; this solution is very expensive, as it requires an additional converter for the amelioration of PQ. A PQ comparison between HVAC and HVDC systems was studied in [17]; the study concluded that HVDCs are a better option than HVAC systems, but no solutions to improve the PQ were proposed. A power compensation scheme to remove the double frequency ripples in active and reactive powers for a VSC-HVDC system was proposed in [18]; this control scheme is able to compensate the active and reactive powers exchanged between the HVDC and the grids when the grid voltages are unbalanced. This compensation was carried out without ripple, however, the proposed strategy was not able to compensate the imbalances in the grid voltages. An overview of a PQ analysis was studied in [19]; the work analyzed several PQ compensators as well as the most common control techniques applied to VSC to improve the PQ. The paper concluded that VSC-HVDCs offer a wide range of functionalities, particularly applied to the PQ improvements of smart grids, and still require in-depth research.

\section{Main Contributions}

Several references have been analyzed in the literature review, concluding that HVDC systems are not usually employed to compensate PQ disturbances that can affect AC grids. This paper proposes a multiterminal multilevel VSC-HVDC system that is able to ameliorate the PQ of the AC grids connected to the VSC terminals. To be precise, the HVDC is able not only to compensate for active power, but also to cancel out sags in the grid voltages and harmonics in the currents that flow through the different AC grids. Balanced and unbalanced voltage sag compensation in a specific AC grid is carried out through the injection of reactive power by the terminal of the HVDC associated with that grid, and by the use of a resonant controller to cancel out the second harmonic component, which is present in the case of imbalances. Moreover, each terminal of the HVDC offers active-power filter functionality to remove harmonics from the current of each AC grid; 
this compensation is performed by using several resonant controllers implemented in a synchronous reference frame (SRF). The result is that the currents that flow through each AC grid are balanced and sinusoidal, yielding balanced and sinusoidal voltages at the PCC. Simulation results show that the control scheme performs effectively in terms of stability, transient response, error in steady-state, and total-harmonic distortion (THD).

The paper is organized as follows: The description of the dynamic model of the multiterminal multilevel VSC-HVDC is presented in Section 2. The topology of the control scheme with PQ capabilities is thoroughly explained in Section 3. Simulation results obtained by using PSCAD ${ }^{\mathrm{TM}} / \mathrm{EMTDC}^{\mathrm{TM}}$ (Power System Computer-Aided Design; Electromagnetic Transients including Direct Current) are presented in Section 4. Finally, the main conclusions are provided in Section 5.

\section{Model of the Multiterminal VSC-HVDC}

The scheme of a multiterminal HVDC system is plotted in Figure 1. In this case, four terminals are connected to their respective AC grids and share the same DC link. Several load types can be connected to the various PCCs by means of breakers (Brk), i.e., linear loads, both balanced and unbalanced loads, and nonlinear loads. Each VSC is connected to its respective AC network by means of a coupling transformer that is modeled by a resistance $R_{m}$ and an inductance $L_{m}$, where the subscript $m$ denotes the number of the terminal, i.e., $m=1,2,3$, and 4 .

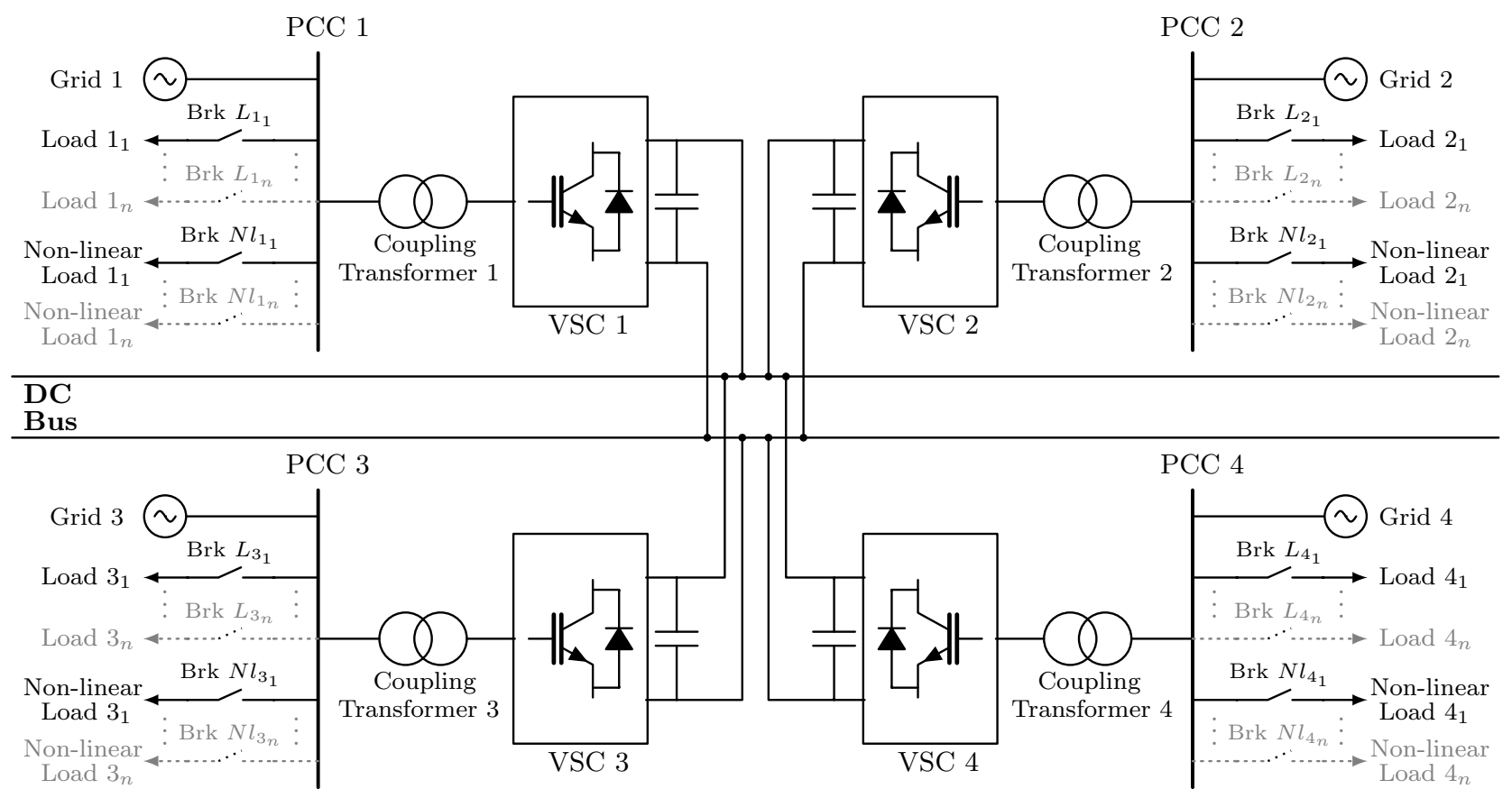

Figure 1. Scheme of a four-terminal high-voltage direct current (HVDC) system. VSC—voltage-source converter.

An NPC multilevel topology is employed for each VSC. Particularly, a three-level NPC converter was chosen (see Figure 2 for more details) owing to its ease of implementation and to the fact that it is a well-established commercial solution compared to other multilevel topologies. The advantages of this configuration can be found in [20], while a comparison between several multilevel topologies can be seen in [21].

The single-phase diagram of the $m$-th terminal of the HVDC system connected to its respective AC grid is shown in Figure 3, where $u_{m}$ is the output voltage of the VSC, $i_{m}$ is the current exchanged between the VSC and the grid, and $v_{m}$ is the voltage at the PCC. The current $i_{\text {Load }_{m}}$ stands for the sum of all the currents drawn by the various loads connected to the PCC, while $v_{g_{m}}$ is the AC grid voltage and $i_{g_{m}}$ is the grid current. Finally, 
the parameters $R_{g_{m}}$ and $L_{g_{m}}$ are the resistance and the inductance, respectively, employed to model the line of the grid.

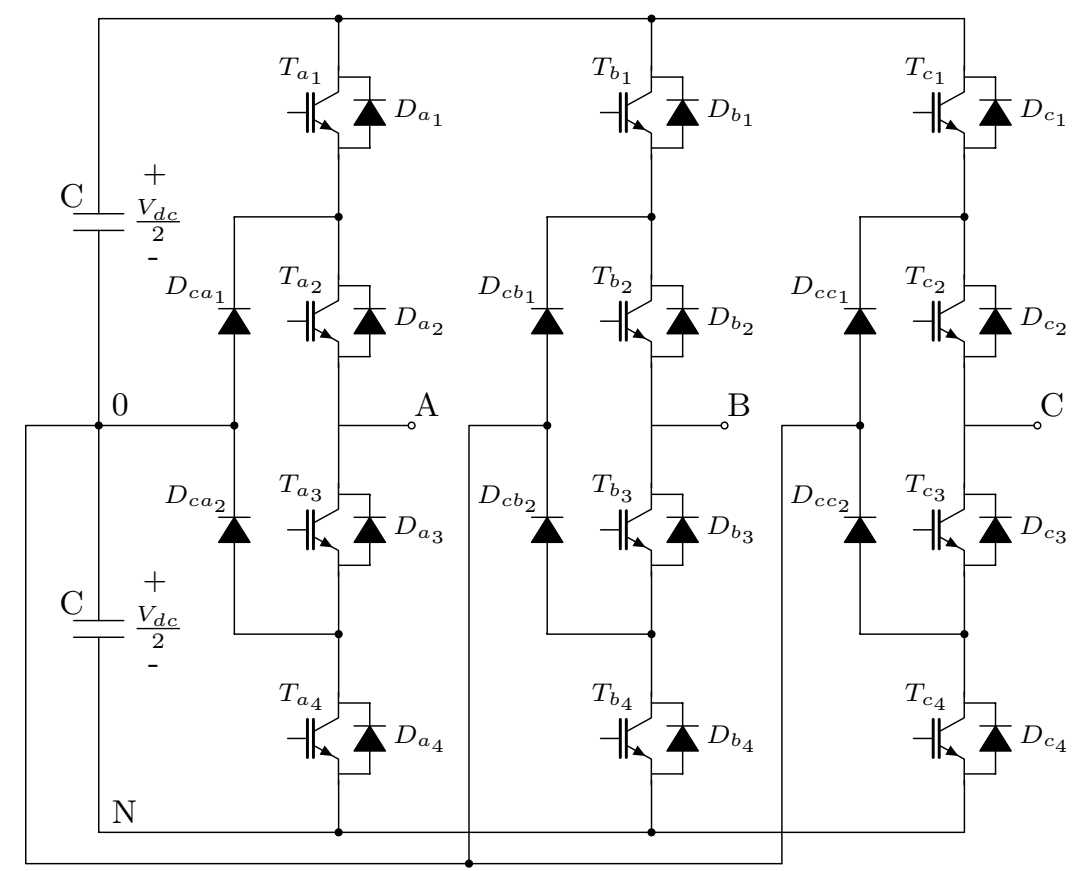

Figure 2. Three-level three-phase neutral-point clamped (NPC) converter.

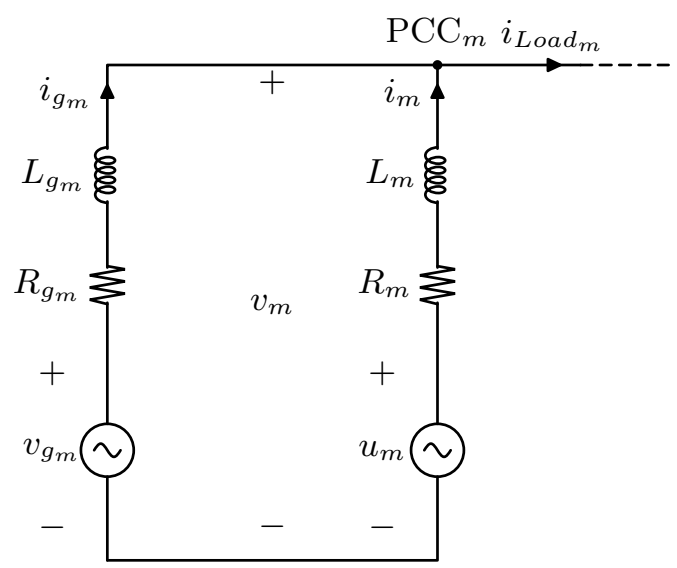

Figure 3. Single-phase equivalent circuit of the $m$-th terminal of the HVDC connected to the grid. PCC-point of common coupling.

A state-space model can be obtained for the current $i_{m}$ by using an SRF together with Park's transformation [22] and under the assumption that a three-wire system is employed, yielding

$$
\frac{d}{d t}\left[\begin{array}{l}
i_{m_{d}} \\
i_{m_{q}}
\end{array}\right]=\left[\begin{array}{cc}
-\frac{R_{m}}{L_{m}} & \omega_{1} \\
-\omega_{1} & -\frac{R_{m}}{L_{m}}
\end{array}\right]\left[\begin{array}{c}
i_{m_{d}} \\
i_{m_{q}}
\end{array}\right]+\frac{1}{L_{m}}\left[\begin{array}{ll}
1 & 0 \\
0 & 1
\end{array}\right]\left[\begin{array}{c}
u_{m_{d}}-v_{m_{d}} \\
u_{m_{q}}
\end{array}\right],
$$

where $i_{m_{d}}$ and $i_{m_{q}}$ are the $d$ and $q$ components of the current $i_{m}$, respectively; $u_{m_{d}}$ and $u_{m_{q}}$ are the $d$ an $q$ components of the output voltage of the VSC, which will be used as control input to regulate the current $i_{m}$; and $v_{m_{d}}$ is the $d$ component of the grid voltage $v_{m}$ that can be seen as a disturbance. The parameter $\omega_{1}$ is the angular frequency of the grid voltage. 
The dynamic system (1) is coupled and must be decoupled in order to implement independent control laws for $i_{m_{d}}$ and $i_{m_{q}}$. This can achieved by rewriting the system (1) as

$$
\frac{d}{d t}\left[\begin{array}{l}
i_{m_{d}} \\
i_{m_{q}}
\end{array}\right]=\left[\begin{array}{cc}
-\frac{R_{m}}{L_{m}} & 0 \\
0 & -\frac{R_{m}}{L_{m}}
\end{array}\right]\left[\begin{array}{c}
i_{m_{d}} \\
i_{m_{q}}
\end{array}\right]+\frac{1}{L_{m}}\left[\begin{array}{ll}
1 & 0 \\
0 & 1
\end{array}\right]\left[\begin{array}{l}
z_{m_{d}} \\
z_{m_{q}}
\end{array}\right],
$$

where the $d$ and $q$ components of the VSC output voltage can be obtained using the following decoupling equations:

$$
\left[\begin{array}{l}
u_{m_{d}} \\
u_{m_{q}}
\end{array}\right]=L_{m}\left[\begin{array}{cc}
0 & -\omega_{1} \\
\omega_{1} & 0
\end{array}\right]\left[\begin{array}{l}
i_{m_{d}} \\
i_{m_{q}}
\end{array}\right]+\left[\begin{array}{c}
z_{m_{d}} \\
z_{m_{q}}
\end{array}\right]+\left[\begin{array}{c}
v_{m_{d}} \\
0
\end{array}\right]
$$

It should be noticed that the $q$ component of $v_{m}$ is zero in the SRF, as explained in [23], which implies that, under balanced conditions, the instantaneous active and reactive powers exchanged between the VSC and the grid at the PCC can be written as

$$
\begin{aligned}
& p_{m}=v_{m_{d}} i_{m_{d}}, \\
& q_{m}=-v_{m_{d}} i_{m_{q}} .
\end{aligned}
$$

The active power $p_{m}$ and the reactive power $q_{m}$ can therefore be controlled by regulating the $d$ and $q$ components, respectively, of the current $i_{m}$. Similarly, the active and reactive powers at the VSC output are

$$
\begin{aligned}
& p_{m_{\mathrm{VSC}}}=u_{m_{d}} i_{m_{d}}+u_{m_{q}} i_{m_{q}}, \\
& q_{m_{\mathrm{VSC}}}=u_{m_{q}} i_{m_{d}}-u_{m_{d}} i_{m_{q}} .
\end{aligned}
$$

Under the assumption of an ideal VSC, the power at the input of the VSC, $p_{m_{i n}{ }_{\text {VSC }}}$, must be equal to the power stored in the DC-link capacitor of the VSC, $p_{m_{\mathrm{DC}_{\mathrm{VSC}}}}$ plus the output power of the VSC:

$$
p_{m_{\text {in } \mathrm{VSC}}}=p_{m_{\mathrm{DC}} \mathrm{VSC}}+p_{m_{\mathrm{VSC}}} .
$$

Moreover, the term $p_{m_{D C_{\mathrm{VSC}}}}$ can be calculated using the following dynamic model:

$$
p_{m_{D C} C_{\mathrm{VSC}}}=v_{m_{\mathrm{DC}}} i_{m_{\mathrm{DC}}}=v_{m_{\mathrm{DC}}} C_{m} \frac{d v_{m_{\mathrm{DC}}}}{d t}=\frac{1}{2} C_{m} \frac{d\left(v_{m_{\mathrm{DC}}}\right)^{2}}{d t},
$$

where $C_{m}$ is the equivalent capacitor of the DC side of the VSC associated with the $m$-th terminal, $v_{m_{\mathrm{DC}}}$ is the voltage across the capacitor $C_{m}$, and $i_{m_{\mathrm{DC}}}$ is the current through the capacitor $C_{m}$. The output power of the VSC can be written as

$$
p_{m_{\mathrm{VSC}}}=p_{m}+p_{m_{\mathrm{tr}}},
$$

where the term $p_{m_{\text {tr }}}$ is the power dissipated in the coupling transformer used to connect the VSC to the AC grid. If this power is neglected [24], then $p_{m_{\mathrm{VSC}}} \approx p_{m}$, and the combination of Equations (4), (6), (8) and (9) yield

$$
\frac{1}{2} C_{m} \frac{d\left(v_{m_{\mathrm{DC}}}\right)^{2}}{d t} \approx p_{m_{i n_{\mathrm{VSC}}}}-v_{m_{d}} i_{m_{d}} .
$$

Equation (11) reveals that if the voltage $v_{m_{\mathrm{DC}}}$ remains constant, all the power at the input of the VSC will be equal to the active power at the PCC, which can be used to inject power to the AC grid or, on the contrary, absorb power from the AC network.

\section{Proposed Control Topology}

Multiterminal VSC-HVDC systems allow the energy to flow between the different AC grids to fulfill the requirements of power demanded by the energy consumption. Moreover, 
a reactive power compensation can be carried out by the VSC-HVDC in order to correct the drop voltage at the PCC owing to the line impedance of the grid and the current through it.

Owing to the various types of loads connected to each PCC, the grid current can contain imbalances and harmonics and, thus, the voltages at each PCC will be polluted. In order to cancel out these disturbances, each VSC in the multiterminal VSC-HVDC system was employed to inject the unbalanced current and the harmonics components necessary for the correct operation of the various loads connected to the PCCs, while maintaining the grid current with a low distortion, thus, yielding a more sinusoidal waveform for the voltages at the PCCs.

In this work, one of the VSCs is in charge of maintaining a regulated DC voltage across the DC bus, thus providing a power slack to guarantee that the power balance is fulfilled. Nevertheless, an additional VSC can be designed to provide a backup of the control of the DC voltage [15]. Figure 4 shows the proposed control topology based on the control scheme of the STATCOM reported in [25].

As the scheme is implemented in the SRF [26], a synchronization method is employed to obtain the angle $\theta_{1}$ necessary to carry out the Park transformation. Several alternatives can be used, although the synchronization scheme chosen in this work is the open-loop estimator explained in [27], owing to its capabilities to operate in the presence of harmonics.
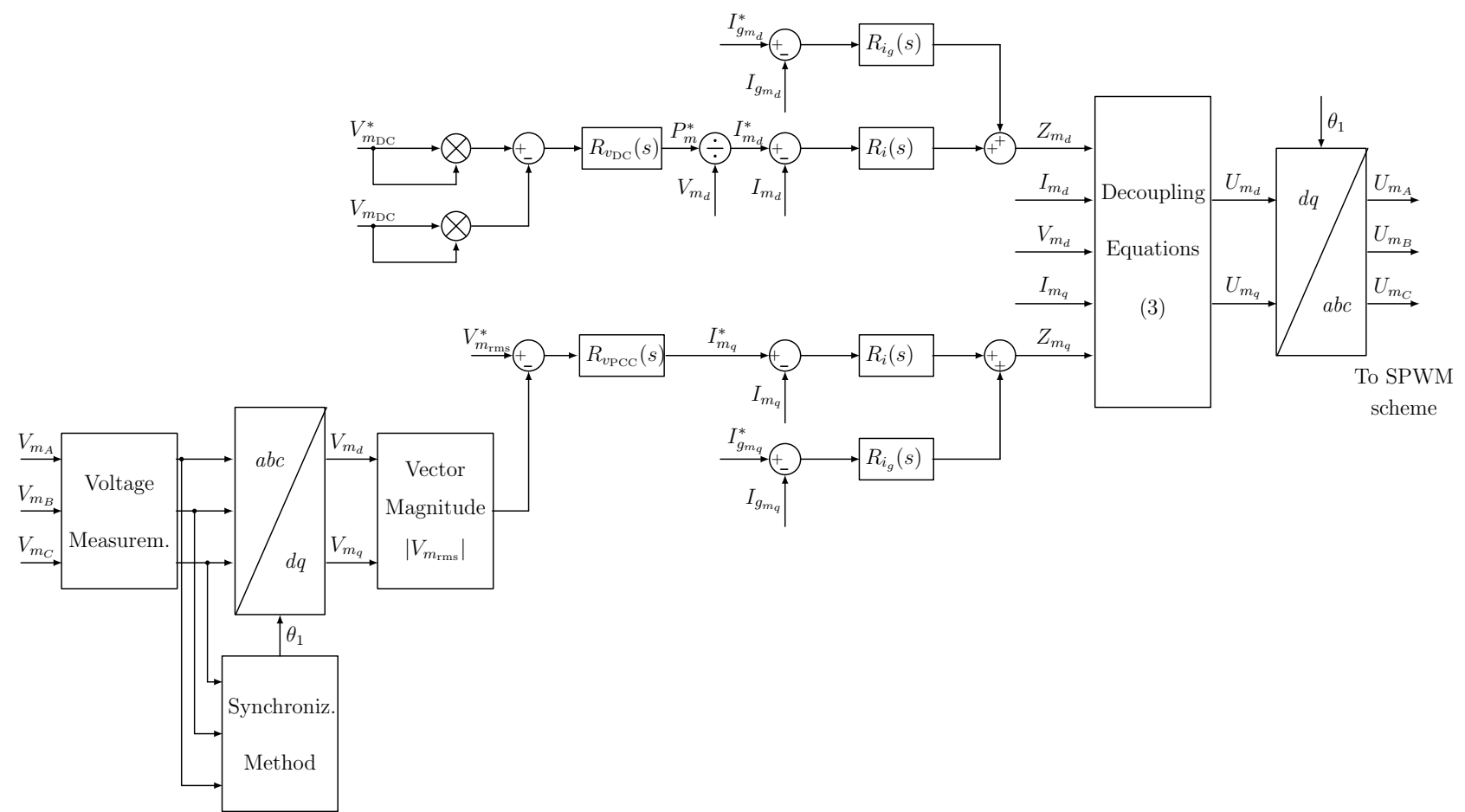

Figure 4. Proposed control scheme of the VSC that regulates the DC voltage across the DC bus. SPWM-sinusoidal pulse-width modulation.

The structure contains several nested control loops to regulate a number of variables compared to their set-point values, denoted by an asterisk: controller $R_{v_{\mathrm{DC}}}(s)$ is in charge of regulating the DC voltage of the complete DC bus, while controller $R_{V_{\mathrm{PCC}}}(s)$ maintains the voltage at the PCC constant; the two controllers $R_{i}(s)$ are designed to regulate the DC component of the current injected into the AC grid by the VSC in both $d$ and $q$ axes, whereas the two regulators $R_{i_{g}}(s)$ are tailored to compensate the harmonics and imbalances of the grid current in both $d$ and $q$ axes. The sum of the control actions provided by $R_{i}(s)$ and $R_{i_{g}}(s)$ yields the variables $Z_{m_{d}}(s)$ and $Z_{m_{q}}(s)$, which are used together with the currents $I_{m_{d}}(s)$ and $I_{m_{q}}(s)$ and the voltage $V_{m_{d}}(s)$ in the decoupling Equation (3) to obtain the $d$ and $q$ components of the output voltage of the VSC. These components are transformed into three-phase voltages by means of the inverse Park Transformation and are driven to a 
sinusoidal pulse-width modulation (SPWM) scheme to implement the firing signals of the switches in the VSC [28].

The complete control scheme to operate a VSC that will not regulate the DC voltage across the DC bus is very similar and is plotted in Figure 5. The difference with the scheme shown in Figure 4 is that the controller $R_{v_{\mathrm{DC}}}(s)$ is not present and the reference of active power can be generated in accordance with a power dispatcher.

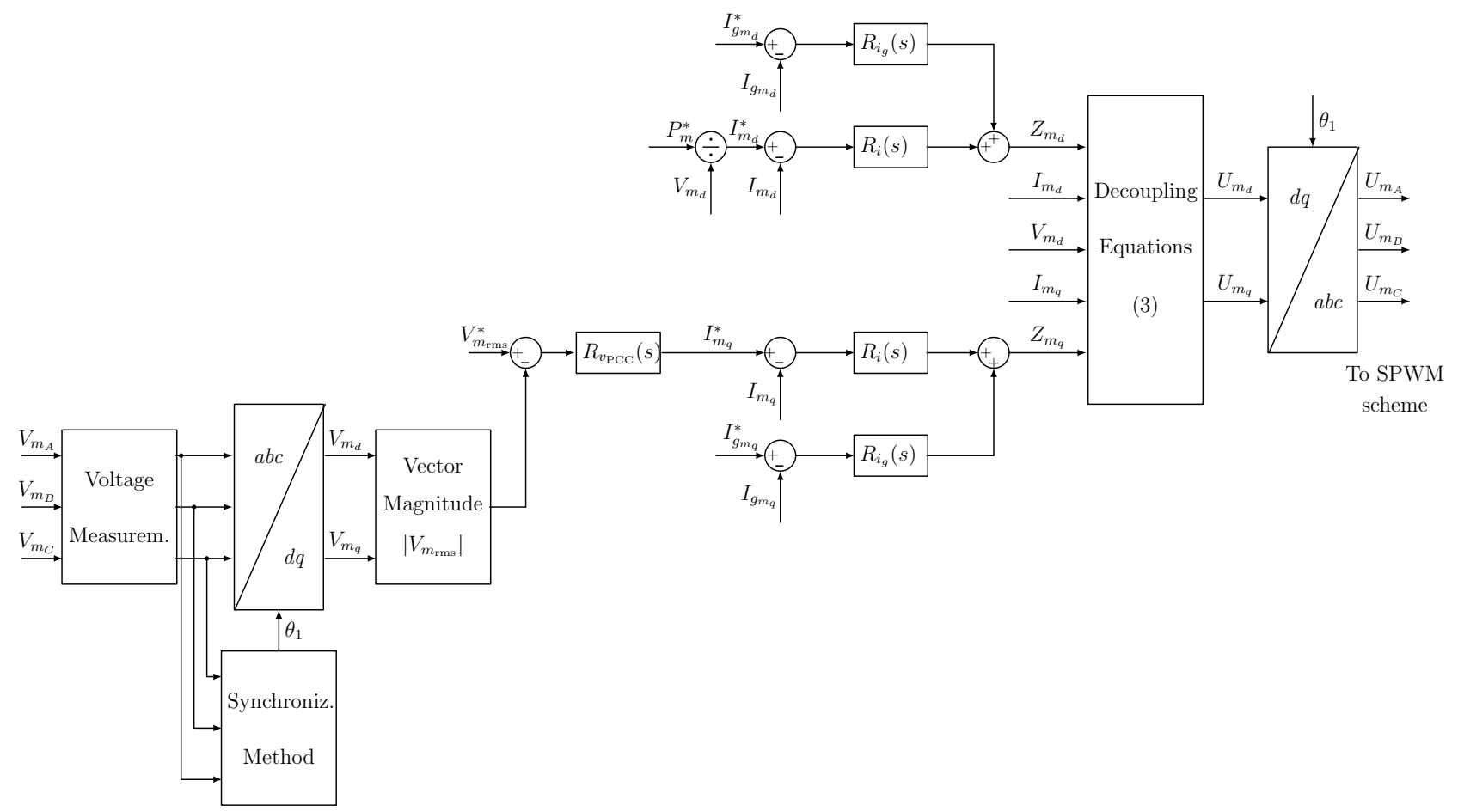

Figure 5. Proposed control scheme of the VSC without regulation of the DC voltage across the DC bus.

\subsection{Regulation of the DC Voltage across the DC Bus}

The DC voltage of the HVDC system is controlled by using a multiloop scheme with two PI controller loops: the inner control loop, $R_{i}(s)$, regulates the $d$ component of the current $i_{m}$ using one of the most well-known scheme to operate with grid-connected VSCs [29]; the outer control loop, $R_{v_{\mathrm{DC}}}(s)$, is in charge of regulating the DC voltage. The output of $R_{v_{\mathrm{DC}}}(s)$ is the reference for the active power, $P_{m}^{*}(s)$, which, divided by the $d$ component of the voltage at the PCC $V_{m_{d}}(s)$, yields the reference for the current, $I_{m_{d}}^{*}(s)$, of the inner control loop.

Let $X_{m_{d}}(s)$ be the output of the controller $R_{i}(s)$ for the $d$ axis. This output can be calculated in accordance with the following PI control law:

$$
X_{m_{d}}(s)=-k_{p} I_{m_{d}}(s)+\frac{k_{i}}{s}\left(I_{m_{d}}^{*}(s)-I_{m_{d}}(s)\right),
$$

where $k_{p}$ and $k_{i}$ are the proportional gain and the integral gain of the PI controller, respectively, and are tailored to control the dynamic system (13) for the $d$ axis, which can be easily obtained from the decoupled plant (2):

$$
P_{i_{m_{d}}}(s)=\frac{I_{m_{d}}(s)}{Z_{m_{d}}(s)}=\frac{\frac{1}{L_{m}}}{s+\frac{R_{m}}{L_{m}}} .
$$

Furthermore, the proposed PI control law for the regulator $R_{v_{\mathrm{DC}}}(s)$ is

$$
P_{m}^{*}(s)=\left(k_{p_{v}}+\frac{k_{i_{v}}}{s}\right)\left[\left(V_{m_{\mathrm{DC}}}^{2}(s)\right)^{*}-\left(V_{m_{\mathrm{DC}}}^{2}(s)\right)\right],
$$


where $k_{p_{v}}$ and $k_{i_{v}}$ are the proportional gain and the integral gain of the controller $R_{v_{\mathrm{DC}}}(s)$, respectively. These gains are designed using the dynamic model (15) in the Laplace domain obtained from (11):

$$
V_{m_{\mathrm{DC}}}^{2}(s)=\frac{2}{C_{m}}\left(P_{m_{i n_{\mathrm{VSC}}}}(s)-P_{m}(s)\right),
$$

where $P_{m_{i n} \mathrm{VSC}}(s)$ is a disturbance input that cannot be controlled and $P_{m}(s)$ is the control input that will be modified to vary $V_{m_{\mathrm{DC}}}^{2}(s)$ and, therefore, the value of the voltage $V_{m_{\mathrm{DC}}}(s)$.

\subsection{Regulation of the Voltage at the PCC}

A similar structure to the one employed in Section 3.1 based on a multiloop control scheme is used to regulate the voltage at the PCC. In this case, the inner control loop, $R_{i}(s)$, controls the $q$ component of the current $i_{m}$, while the outer control loop, $R_{v_{\mathrm{PCC}}}(s)$, is the responsible for regulating the root-mean square (RMS) value of the voltage at the PCC. The output of $R_{v_{\text {PCC }}}(s)$ is the reference for the $q$ component of the current injected by the VSC, $I_{m_{q}}^{*}(s)$.

The control law for $R_{i}(s)$ in the $q$ axis is the same as the one obtained for the $d$ axis:

$$
X_{m_{q}}(s)=-k_{p} I_{m_{q}}(s)+\frac{k_{i}}{s}\left(I_{m_{q}}^{*}(s)-I_{m_{q}}(s)\right),
$$

where $X_{m_{q}}(s)$ is the output of the controller $R_{i}(s)$ for the $q$ axis and the gains $k_{p}$ and $k_{i}$ are calculated to control the dynamic system (17) for the $q$ axis, which are obtained from the decoupled plant (2):

$$
P_{i_{m_{q}}}(s)=\frac{I_{m_{q}}(s)}{Z_{m_{q}}(s)}=\frac{\frac{1}{L_{m}}}{s+\frac{R_{m}}{L_{m}}} .
$$

It should be noticed that Equations (13) and (17) contain the same parameters and, under the assumption that the same design specifications hold for the regulator $R_{i}(s)$, the gains of $R_{i}(s)$ will, therefore, be equal in both axes.

The controller $R_{v_{\text {PCC }}}(s)$ is designed under the assumption of a balanced three-phase system, which yields a constant RMS value for the voltage. For that reason, a PI controller is also proposed with the following control law:

$$
I_{m_{q}}^{*}(s)=\left(k_{p_{v_{\mathrm{AC}}}}+\frac{k_{i_{v_{\mathrm{AC}}}}}{s}\right)\left(V_{m_{\mathrm{rms}}}^{*}-V_{m_{\mathrm{rms}}}\right),
$$

where $k_{p_{v_{A C}}}$ and $k_{p_{v_{A C}}}$ are the proportional and integral gains, respectively, of the controller $R_{v_{\text {PCC }}}(s)$. These parameters must be carefully calculated as the dynamic model of the grid and loads is unknown and an arbitrary design might render the system unstable.

\subsection{Compensation of Imbalances and Harmonics of the Grid Current}

When unbalanced loads or nonlinear loads are connected to the AC grid, imbalances and harmonics appear in the current that flows through the grid, which cause a distorted and unbalanced voltage at the PCC in weak grids owing to the line impedance. The HVDC system can be used to compensate these disturbances and improve the power quality at the various PCCs, resembling the behavior of an active power filter. This section proposes a control scheme based on proportional-resonant (PR) controllers to cancel out the imbalances and harmonics in the grid current. Usually, the most frequent harmonics present in the voltage at the PCC are uneven components [30]. These components are transformed into even harmonics in the SRF [27]. Moreover, imbalances in the fundamental component are transformed into second harmonic components in the SRF. For that reason, the use of several resonant regulators tuned at even harmonics, based on the scheme reported in [31], is proposed to remove the harmonics and the imbalances from the grid current. The general transfer function of these resonant controllers is 


$$
R_{h_{n}}(s)=\overbrace{k_{h_{n}} \frac{s-a_{n}}{s-b_{n}}}^{R_{a_{n}}(s)} \overbrace{\frac{s}{s^{2}+\omega_{h_{n}}^{2}}}^{R_{b_{n}}(s)},
$$

where the transfer function $R_{a_{n}}(s)$ is a phase-lead or phase-lag compensator designed to fulfill the specifications of the controller, and the term $R_{b_{n}}(s)$ is the resonant regulator tuned at the frequency $\omega_{h_{n}}$. $R_{b_{n}}(s)$ exhibits a band-pass behavior that is useful to design the regulator without considering the remaining resonant controllers [32].

Figure 6 shows the control scheme that employs several resonant regulators to compensate the imbalances and the harmonics in the grid current. The scheme also plots the implementation of the inner control loop for the regulation of the current injected by the VSC. The scheme is implemented in both $d$ and $q$ axes. As the grid current should not contain either imbalances or harmonics, the reference of the grid current, $I_{g m}^{*}(s)$, must be set to zero. In accordance with Figure 6, the resulting regulator $R_{i_{g}}(s)$ that is present in Figures 4 and 5 is the sum of the various resonant controllers tuned at different frequencies:

$$
R_{i_{g}}(s)=R_{h_{1}}(s)+R_{h_{2}}(s)+R_{h_{3}}(s)+\cdot+R_{h_{n-2}}(s)+R_{h_{n-1}}(s)+R_{h_{n}}(s) .
$$

As an example, Figure 7 shows the magnitude of the frequency response for a regulator $R_{i_{g}}(s)$ designed to compensate the 2nd, 6th, 12th, and 18th harmonic components in the SRF. It can be seen that $R_{i_{g}}(s)$ exhibits infinite gain at the selected frequencies with band-pass behavior, which implies that $R_{i_{g}}(s)$ is suitable for compensating harmonics at these frequencies.

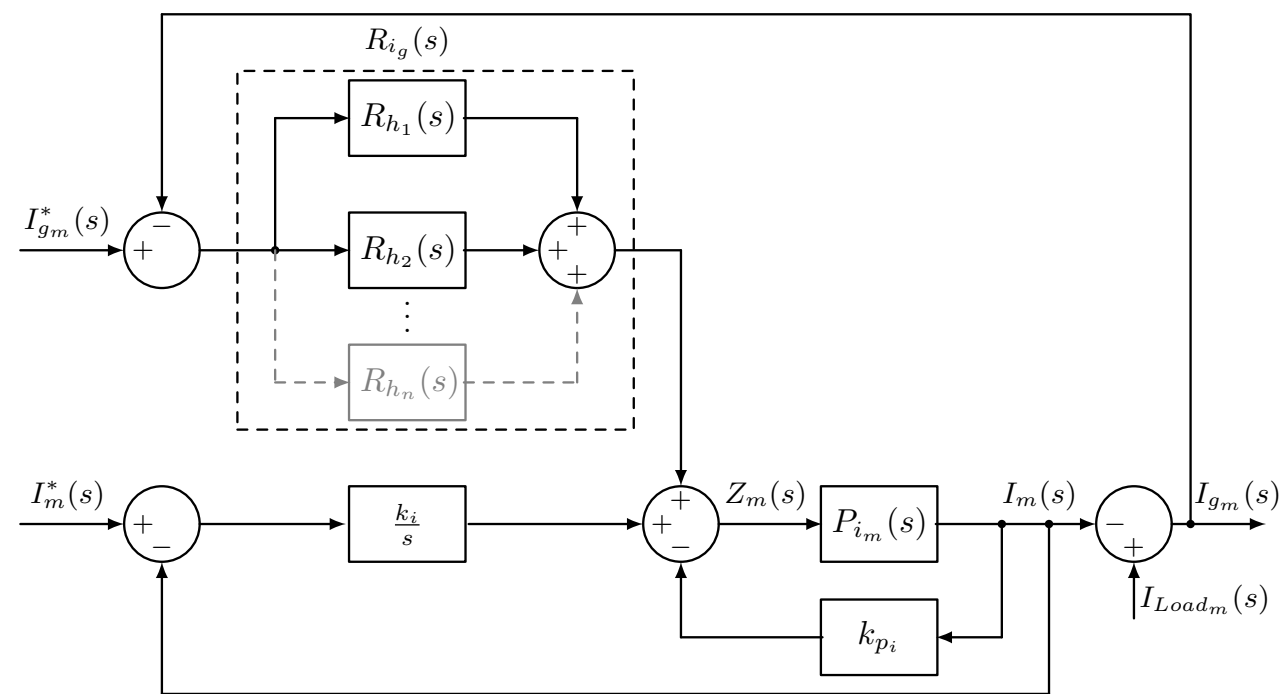

Figure 6. Proposed control scheme for the compensation of imbalances and harmonics in the grid current together with the inner control loop for the control of the current injected by the VSC. 


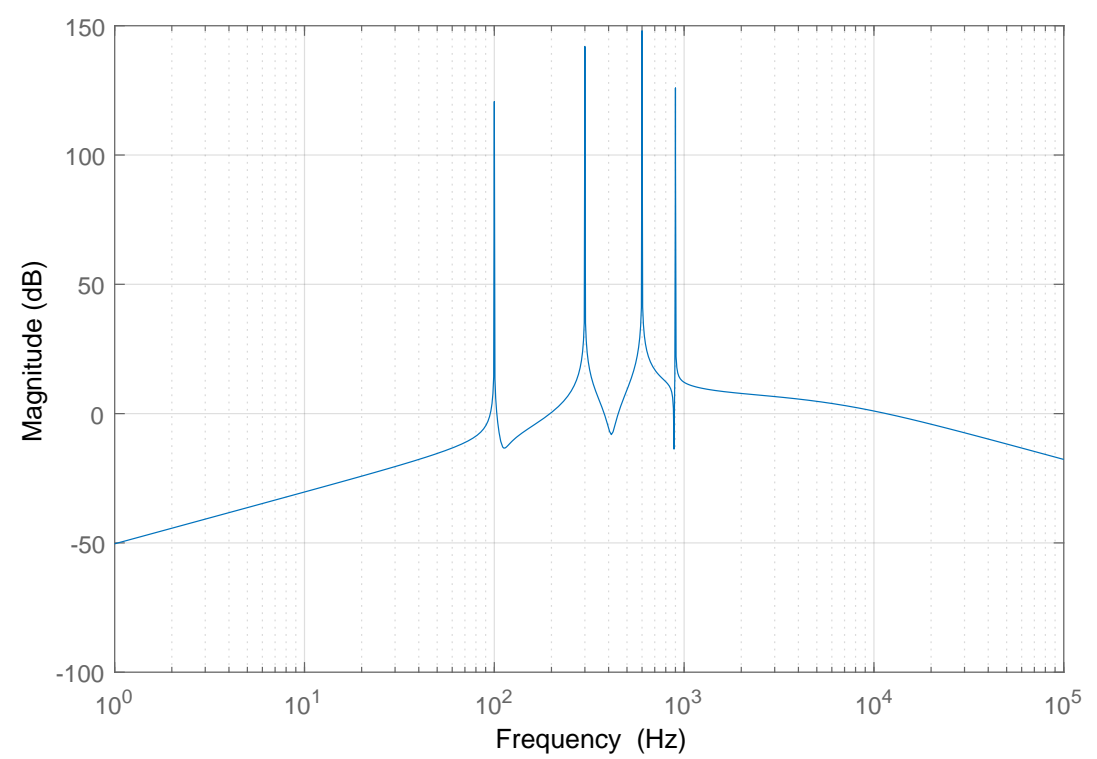

Figure 7. Magnitude (dB) of the Bode plot for several resonant controllers.

\section{Case Study}

A four-terminal HVDC system such as the one depicted in Figure 1 has been simulated using PSCAD ${ }^{\mathrm{TM}} / \mathrm{EMTDC}^{\mathrm{TM}}$. Four AC grids are interconnected by means of the HVDC system. The main features of these networks are as follows:

- AC Grid 1: $11 \mathrm{kV}$ and $50 \mathrm{~Hz}$, inductance of the line $L_{g_{1}}=2 \mathrm{mH}$.

- $\quad$ AC Grid 2: $13.8 \mathrm{kV}$ and $50 \mathrm{~Hz}$, inductance of the line $L_{g_{2}}=1 \mathrm{mH}$.

- AC Grid 3: $13.8 \mathrm{kV}$ and $50 \mathrm{~Hz}$, inductance of the line $L_{g_{3}}=1.5 \mathrm{mH}$.

- AC Grid 4: $11 \mathrm{kV}$ and $50 \mathrm{~Hz}$, inductance of the line $L_{g_{1}}=1.2 \mathrm{mH}$.

The HVDC system employs four three-level three-phase NPC VSCs, which are connected to their respective AC grids by means of four coupling transformers with a winding ratio of $20 \mathrm{KV} / 60 \mathrm{KV}$ and star/star connection. These transformers have been considered ideal, and additional inductive-resistive elements have, therefore, been added to model the resistances and the inductances of the transformers, which are summarized in Table 1 in reference to the $20 \mathrm{KV}$, primary side of the coupling transformers.

Table 1. Resistance and inductance values of the coupling transformers.

\begin{tabular}{lcc}
\hline Coupling Transformer & Resistance $\boldsymbol{R}_{\boldsymbol{m}}$ & Inductance $\boldsymbol{L}_{\boldsymbol{m}}$ \\
\hline Coupling transformer 1 & $R_{1}=6 \mathrm{~m} \Omega$ & $L_{1}=1.5 \mathrm{mH}$ \\
Coupling transformer 2 & $R_{2}=5 \mathrm{~m} \Omega$ & $L_{2}=1.2 \mathrm{mH}$ \\
Coupling transformer 3 & $R_{3}=3 \mathrm{~m} \Omega$ & $L_{3}=1.0 \mathrm{mH}$ \\
Coupling transformer 4 & $R_{4}=4 \mathrm{~m} \Omega$ & $L_{4}=1.2 \mathrm{mH}$ \\
\hline
\end{tabular}

Each VSC employs two series-connected capacitors of $660 \mu \mathrm{F}$, and the DC bus line has been modeled as ideal, therefore, yielding a DC bus capacitor of $1320 \mu \mathrm{F}$. The switching frequency of each VSC is equal to $5950 \mathrm{~Hz}$, and ideal insulated-gate bipolar transistors (IGBTs) are used as switches in each VSC. The voltage across the DC bus is set to $80 \mathrm{kV}$. Several linear loads and one nonlinear load are connected to the PCC of each AC grid by means of circuit breakers. In all cases, the same nonlinear load is used, which is composed of a three-phase full-bridge uncontrolled rectifier that feeds an inductive DC load with a constant current of $2 \mathrm{kA}$. This nonlinear load causes odd harmonics in the AC side current of the rectifier [33]. The main features of the linear loads are the following:

1. AC grid 1.

- Balanced load 1: active power $20 \mathrm{MW}$ and reactive power $11 \mathrm{MVAr}$; connected at instant $t=0.25 \mathrm{~s}$. 
- $\quad$ Balanced load 2: active power $30 \mathrm{MW}$ and reactive power $15 \mathrm{MVAr}$; connected at instant $t=0.4 \mathrm{~s}$.

- Unbalanced load 1 (resistive load): consumption of $8 \mathrm{MW}$ in phase A, consumption of $8 \mathrm{MW}$ in phase $\mathrm{B}$, and consumption of $1.6 \mathrm{MW}$ in phase $\mathrm{C}$; connected at instant $t=0.8 \mathrm{~s}$.

2. AC grid 2.

- $\quad$ Balanced load 1: active power $25 \mathrm{MW}$ and reactive power $12 \mathrm{MVAr}$; connected at instant $t=0.25 \mathrm{~s}$.

- $\quad$ Balanced load 2: active power $35 \mathrm{MW}$ and reactive power $15 \mathrm{MVAr}$; connected at instant $t=0.4 \mathrm{~s}$.

- Unbalanced load 1 (resistive load): consumption of 1.6 MW in phase A, consumption of $20 \mathrm{MW}$ in phase $\mathrm{B}$, and consumption of $20 \mathrm{MW}$ in phase C; connected at instant $t=0.8 \mathrm{~s}$.

3. AC grid 3.

- $\quad$ Balanced load 1: active power $15 \mathrm{MW}$ and reactive power $8 \mathrm{MVAr}$; connected at instant $t=0.25 \mathrm{~s}$.

- $\quad$ Balanced load 2: active power $25 \mathrm{MW}$ and reactive power $16 \mathrm{MVAr}$; connected at instant $t=0.4 \mathrm{~s}$.

- Unbalanced load 1 (resistive load): consumption of $2 \mathrm{MW}$ in phase A, consumption of $8 \mathrm{MW}$ in phase $\mathrm{B}$, and consumption of $2 \mathrm{MW}$ in phase $\mathrm{C}$; connected at instant $t=0.8 \mathrm{~s}$.

4. AC grid 4.

- $\quad$ Balanced load 1: active power $25 \mathrm{MW}$ and reactive power $15 \mathrm{MVAr}$; connected at instant $t=0.25 \mathrm{~s}$.

- $\quad$ Balanced load 2: active power $35 \mathrm{MW}$ and reactive power $10 \mathrm{MVAr}$; connected at instant $t=0.4 \mathrm{~s}$.

- Unbalanced load 1 (resistive load): consumption of 1.4 MW in phase A, consumption of $10 \mathrm{MW}$ in phase $\mathrm{B}$, and consumption of 1.4 MW in phase $\mathrm{C}$; connected at instant $t=0.8 \mathrm{~s}$.

The four nonlinear loads are connected, simultaneously, at instant $t=0.5 \mathrm{~s}$. Terminal 1 is in charge of maintaining the voltage across the DC bus at $80 \mathrm{kV}$, while the other terminals operate as power dispatchers: Terminal 2 injects $20 \mathrm{MW}$ into AC grid 2 at instant $t=2 \mathrm{~s}$, whereas, at $t=2.5 \mathrm{~s}$, it absorbs $10 \mathrm{MW}$ from AC grid 2; terminal 3 injects $25 \mathrm{MW}$ and $15 \mathrm{MW}$ at instants $t=1 \mathrm{~s}$ and $t=1.5 \mathrm{~s}$, respectively, into AC grid 3 . Finally, terminal 4 injects $10 \mathrm{MW}$ into AC grid 4 at instant $t=1 \mathrm{~s}$, and it absorbs $30 \mathrm{MW}$ from AC grid 4 at instant $t=1.5 \mathrm{~s}$.

The regulators $R_{i}(s)$ and $R_{v_{\mathrm{DC}}}(s)$ have been calculated using the pole placement technique [34]. The design specification for the controller $R_{i}(s)$ is to choose real poles in order to avoid overshoots in the time response. With this criterion, the location of the two closed-loop poles is chosen to be $-1200 \mathrm{rad} / \mathrm{s}$, and the resulting parameters are shown in Table 2. The poles of the outer closed-loop system obtained with $R_{v_{D C}}(s)$ are chosen to be slower than the poles of the inner control loop; in this case, the poles are placed at $p_{1}=-25 \mathrm{rad} / \mathrm{s}$ and $p_{2}=-150 \mathrm{rad} / \mathrm{s}$, yielding the following parameters: $k_{p_{v}}=-0.1155$ and $k_{i_{v}}=-2.475$.

Table 2. Parameters of the controllers $R_{i}(s)$ for each terminal.

\begin{tabular}{ccccc}
\hline & Terminal 1 & Terminal 2 & Terminal 3 & Terminal 4 \\
\hline$k_{p}$ & 3.594 & 2.876 & 2.397 & 2.876 \\
\hline$k_{i}$ & 2160 & 1728 & 1440 & 1728 \\
\hline
\end{tabular}


The parameters of the regulator $R_{v_{\text {PCC }}}(s)$ are chosen after following a trial-error procedure, as the plant contains uncertainties. In this case study, the chosen parameters for the four regulators $R_{v_{\mathrm{PCC}}}(s)$ are $k_{p_{v_{\mathrm{AC}}}}=-0.5$ and $k_{i_{v_{\mathrm{AC}}}}=-50$. The controller $R_{v_{\mathrm{PCC}}}(s)$ is activated at instant $t=0.5 \mathrm{~s}$.

The controller $R_{i_{g}}(s)$ is designed to compensate the imbalances in the grid current and the harmonics caused by the nonlinear loads. Recalling that these harmonics are uneven components, they are transformed into the components $h=2,6,12,18,24,30 \ldots$ in the SRF. Hence, the regulator $R_{i_{g}}(s)$ is composed of five resonant controllers in parallel, tailored to compensate the $2 \mathrm{nd}, 6 \mathrm{th}, 12 \mathrm{th}, 18 \mathrm{th}$, and $24 \mathrm{th}$ harmonics in the SRF. The parameters of the various regulators $R_{a_{n}}(s)$ are obtained using the frequency response method [35] with the design specifications of a phase margin of $60^{\circ}$ at the following crossover gain frequencies: $\omega_{o_{1}}=1.05 \omega_{h_{1}}$, with $\omega_{h_{1}}=2 \omega_{1}$, i.e., the 2 nd harmonic; $\omega_{o_{2}}=1.2 \omega_{h_{2}}$, with $\omega_{h_{2}}=6 \omega_{1}$, i.e., the 6th harmonic; $\omega_{0_{3}}=1.2 \omega_{h_{3}}$, with $\omega_{h_{3}}=12 \omega_{1}$, i.e., the 12th harmonic; $\omega_{0_{4}}=1.05 \omega_{h_{4}}$, with $\omega_{h_{4}}=18 \omega_{1}$, i.e., the 18th harmonic; and $\omega_{0_{5}}=1.05 \omega_{h_{5}}$, with $\omega_{h_{5}}=24 \omega_{1}$, i.e., the 24th harmonic. The resulting parameters of the regulators $R_{a_{n}}(s)$ are shown in Table 3. The controller $R_{i_{g}}(s)$ is activated at instant $t=1.2 \mathrm{~s}$. The total simulation time is $3 \mathrm{~s}$.

Table 3. Parameters of the transfer functions $R_{a_{n}}(s)$ for each terminal.

\begin{tabular}{ccccc}
\hline \multicolumn{5}{c}{ Terminal 1 } \\
\hline$R_{a_{1}}(s)$ & $R_{a_{2}}(s)$ & $R_{a_{3}}(s)$ & $R_{a_{4}}(s)$ & $R_{a_{5}}(s)$ \\
\hline$k_{h_{1}}=26.76$ & $k_{h_{2}}=943.48$ & $k_{h_{3}}=3.76 \times 10^{3}$ & $k_{h_{4}}=1.97 \times 10^{3}$ & $k_{h_{5}}=3.50 \times 10^{3}$ \\
$a_{1}=-3.4 \times 10^{-3}$ & $a_{2}=-1 \times 10^{-3}$ & $a_{3}=-5.1 \times 10^{-4}$ & $a_{4}=-4.1 \times 10^{-4}$ & $a_{5}=-2.9 \times 10^{-4}$ \\
$b_{1}=-1.7 \times 10^{-4}$ & $b_{2}=-5.1 \times 10^{-5}$ & $b_{3}=-2.5 \times 10^{-5}$ & $b_{4}=-2.0 \times 10^{-5}$ & $b_{5}=-1.5 \times 10^{-5}$ \\
\hline \multicolumn{5}{c}{ Terminal 2 } \\
\hline$R_{a_{1}}(s)$ & $R_{a_{2}}(s)$ & $R_{a_{3}}(s)$ & $R_{a_{4}}(s)$ & $R_{a_{5}}(s)$ \\
\hline$k_{h_{1}}=19.74$ & $k_{h_{2}}=754.10$ & $k_{h_{3}}=3.01 \times 10^{3}$ & $k_{h_{4}}=1.57 \times 10^{3}$ & $k_{h_{5}}=2.80 \times 10^{3}$ \\
$a_{1}=-3.4 \times 10^{-3}$ & $a_{2}=-1 \times 10^{-3}$ & $a_{3}=-5.1 \times 10^{-4}$ & $a_{4}=-3.9 \times 10^{-4}$ & $a_{5}=-2.9 \times 10^{-4}$ \\
$b_{1}=-1.7 \times 10^{-4}$ & $b_{2}=-5.1 \times 10^{-5}$ & $b_{3}=-2.6 \times 10^{-5}$ & $b_{4}=-1.9 \times 10^{-5}$ & $b_{5}=-1.5 \times 10^{-5}$ \\
\hline \multicolumn{5}{c}{ Terminal 3 } \\
\hline$R_{a_{1}}(s)$ & $R_{a_{2}}(s)$ & $R_{a_{3}}(s)$ & $R_{a_{4}}(s)$ & $R_{a_{5}}(s)$ \\
\hline$k_{h_{1}}=16.43$ & $k_{h_{2}}=628.07$ & $k_{h_{3}}=2.51 \times 10^{3}$ & $k_{h_{4}}=1.31 \times 10^{3}$ & $k_{h_{5}}=2.33 \times 10^{3}$ \\
$a_{1}=-3.4 \times 10^{-3}$ & $a_{2}=-1 \times 10^{-3}$ & $a_{3}=-5.1 \times 10^{-4}$ & $a_{4}=-3.9 \times 10^{-4}$ & $a_{5}=-2.9 \times 10^{-4}$ \\
$b_{1}=-1.7 \times 10^{-4}$ & $b_{2}=-5.1 \times 10^{-5}$ & $b_{3}=-2.5 \times 10^{-5}$ & $b_{4}=-1.9 \times 10^{-5}$ & $b_{5}=-1.5 \times 10^{-5}$ \\
\hline \multicolumn{5}{c}{ Terminal 4} \\
\hline$R_{a_{1}}(s)$ & & $R_{a_{3}}(s)$ & & $R_{a_{5}}(s)$ \\
\hline$k_{h_{1}}=19.74$ & $R_{a_{2}}(s)$ & $k_{h_{3}}=3.01 \times 10^{3}$ & $k_{h_{4}}=1.57 \times 10^{3}$ & $k_{h_{5}}=2.80 \times 10^{3}$ \\
$a_{1}=-3.4 \times 10^{-3}$ & $a_{2}=-1 \times 10^{-3}$ & $a_{3}=-5.1 \times 10^{-4}$ & $a_{4}=-3.9 \times 10^{-4}$ & $a_{5}=-2.9 \times 10^{-4}$ \\
$b_{1}=-1.7 \times 10^{-4}$ & $b_{2}=-5.1 \times 10^{-5}$ & $b_{3}=-2.5 \times 10^{-5}$ & $b_{4}=-1.9 \times 10^{-5}$ & $b_{5}=-1.5 \times 10^{-5}$ \\
\hline \multicolumn{5}{c}{}
\end{tabular}

Figure 8 shows the time response of the voltage of each of the four PCCs to which the HVDC system is connected: Before instant $t=0.5 \mathrm{~s}$, voltage sags with different amplitudes are present in all PCCs owing to the connections of the linear and nonlinear loads to their respective AC grids. The greatest voltage sag takes place at $\mathrm{PCC}_{1}$ with an amplitude around $13 \%$. Once the regulators $R_{v_{\text {PCC }}}(s)$ are activated in the terminals of the HVDC systems at $t=0.5 \mathrm{~s}$, all voltages at the PCCs increase their amplitudes until the steady-state value of 1 p.u is reached. Although there are changes in these voltages when the references of the active powers of the terminal power dispatchers are modified, the steady-state error in the voltage is zero owing to the integral action of the controller $R_{v_{\text {PCC }}}(s)$. 

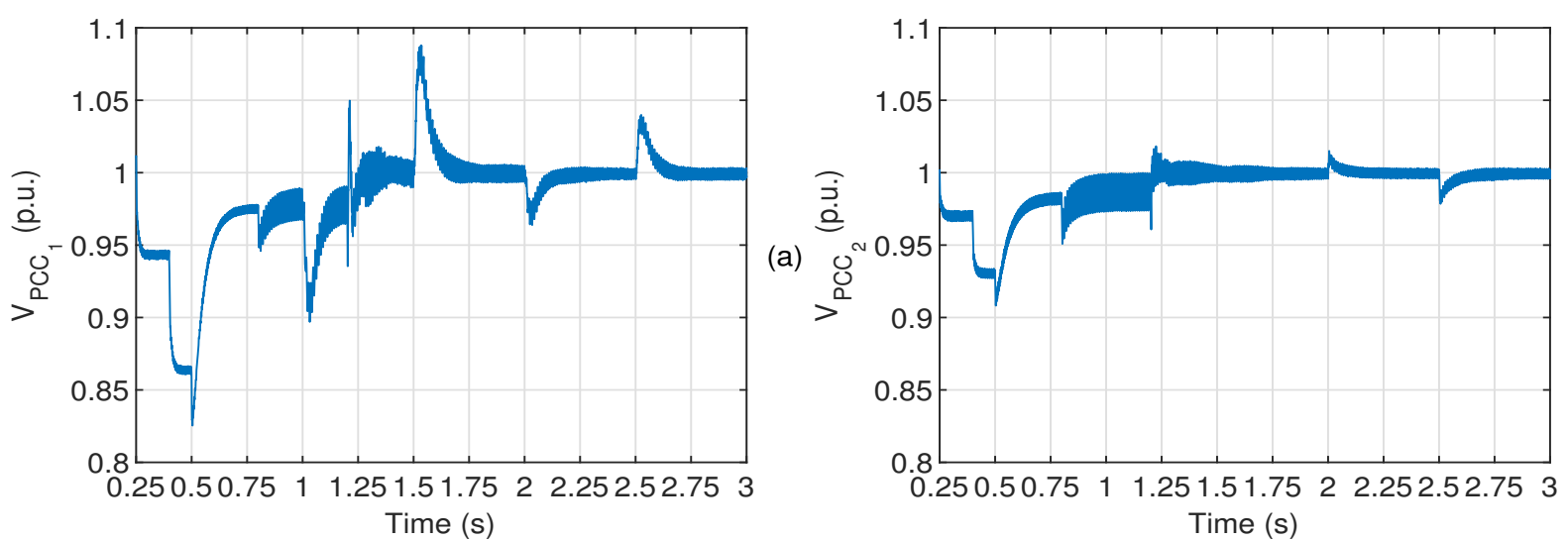

(b)
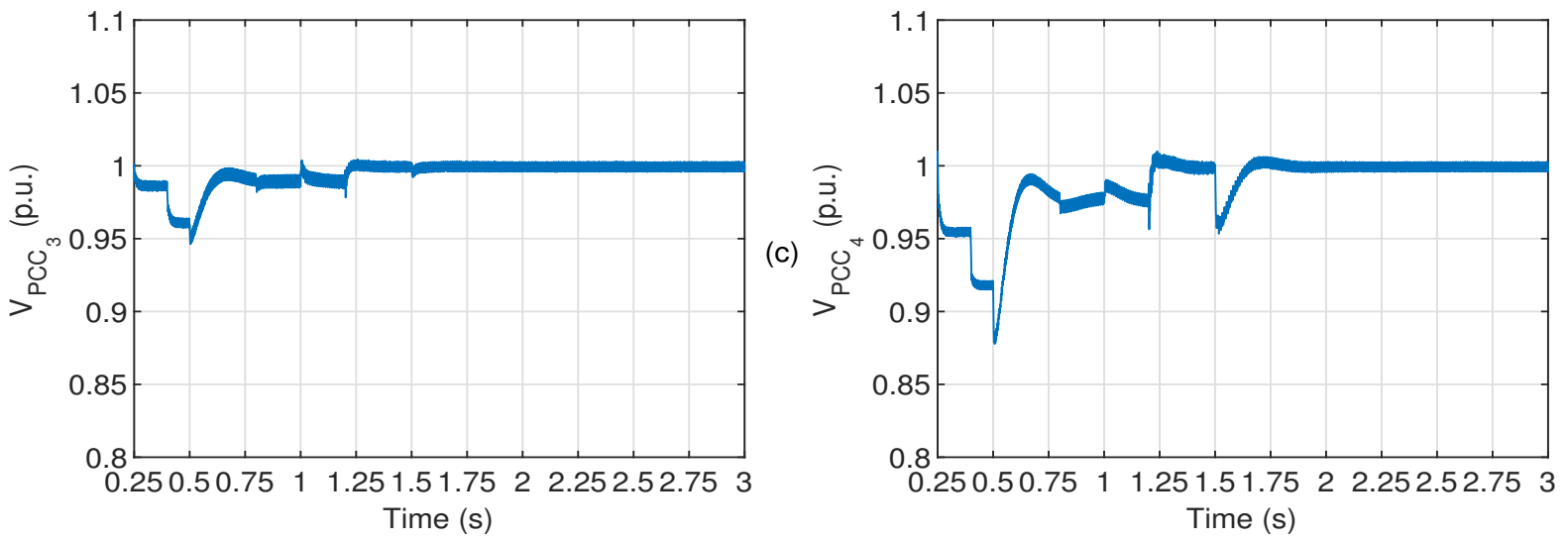

(d)

Figure 8. Evolution of the voltages at the four PCCs in p.u: (a) $V_{\mathrm{PCC}_{1}}$, (b) $V_{\mathrm{PCC}_{2}}$, (c) $V_{\mathrm{PCC}_{3}}$, and (d) $V_{\mathrm{PCC}_{4}}$.

The voltage across the DC bus is plotted in Figure 9: A double frequency ripple is present when imbalances begin to be compensated [18]. Moreover, even voltage harmonics are present in the voltage waveform when the harmonics of the grid currents are compensated by each terminal of the HVDC system. However, the DC value of the voltage across the DC bus remains around $80 \mathrm{kV}$, despite the disturbances caused by changes in the references of the active powers of the terminal power dispatchers.

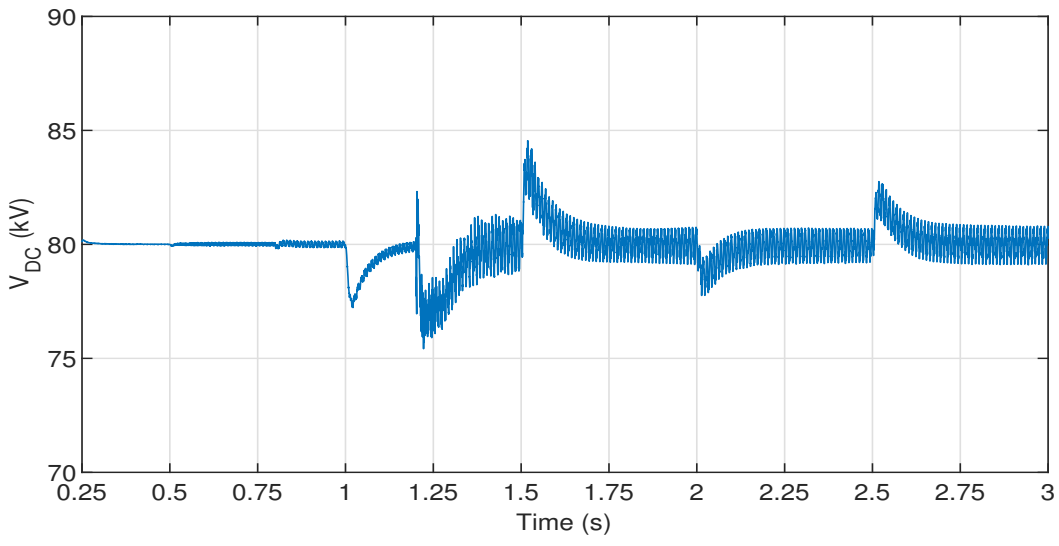

Figure 9. Time response of the voltage across the DC bus.

The process of the transmission of active power in the HVDC from one terminal to another is shown in Figure 10, which plots in blue color the injected/absorbed active powers by the four terminals into/from their respective AC grids (if the active power is positive, it is considered that the terminal injects active power into the grid, in accordance 
with [7]). It should be noticed that the VSC connected to terminal 1 keeps the power balanced owing to the control of the voltage across the DC bus; e.g., at instant $t=2.75 \mathrm{~s}$, the active powers of the three dispatcher terminals are $p_{2}=-10 \mathrm{MW}, p_{3}=15 \mathrm{MW}$, and $p_{4}=-25 \mathrm{MW}$, respectively, yielding a power balance at terminal 1 equal to $p_{1}=20 \mathrm{MW}$; the actual active power injected by the terminal 1 is, however, slightly higher owing to the losses in the coupling transformers, as shown in Figure 10a.
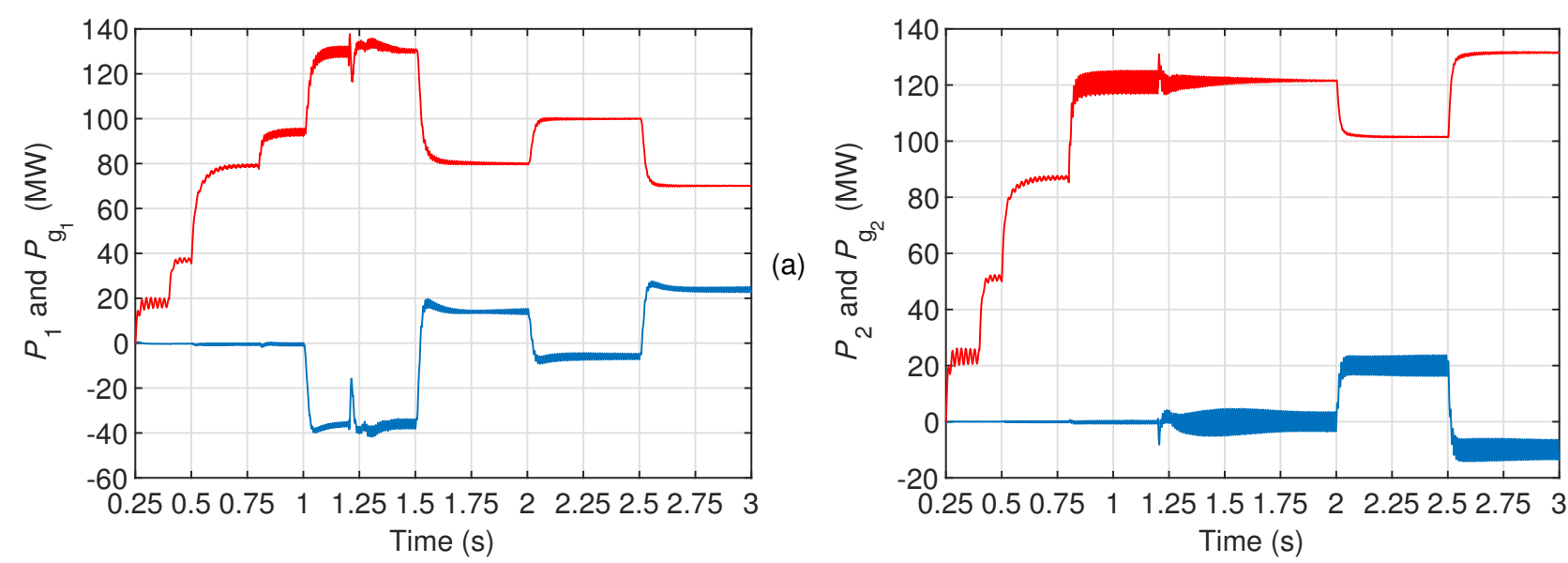

(b)
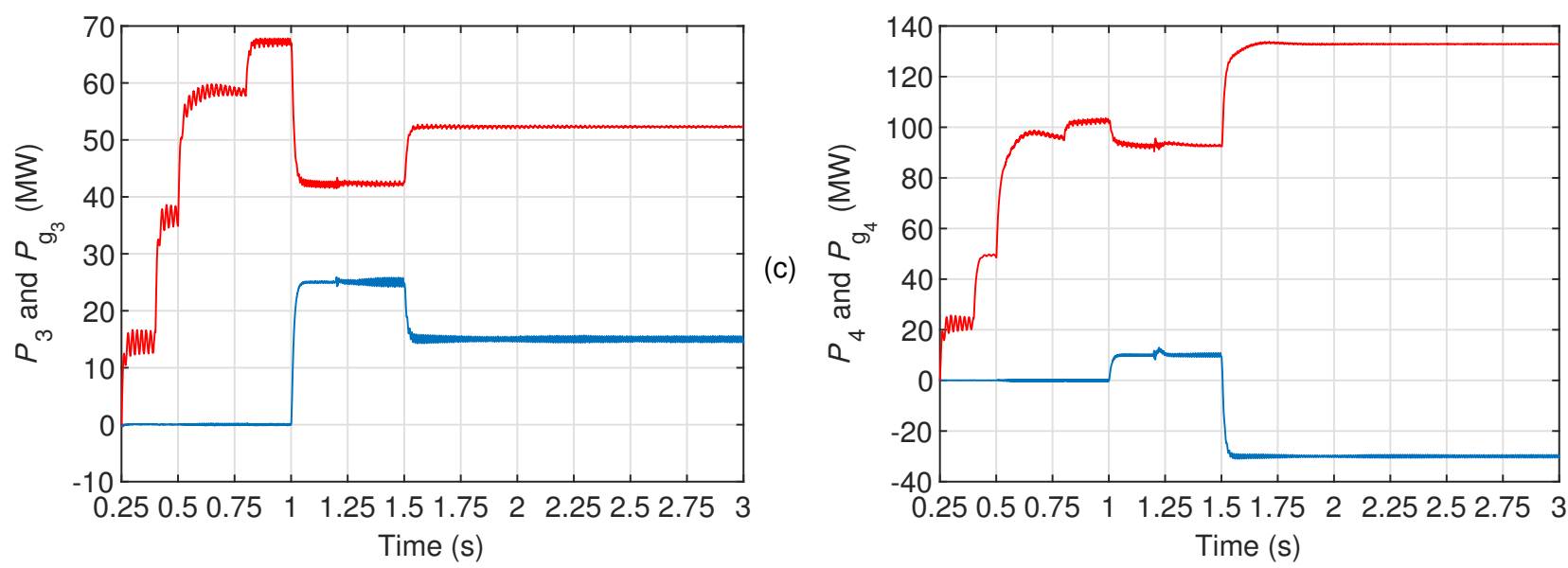

(d)

Figure 10. Evolution of the active powers injected/absorbed by each terminal into/from its respective AC grid and the total active power flow in each AC grid: (a) active power of terminal $1 p_{1}$ (blue color) and active power of AC grid $1 p_{g_{1}}$ (red color); (b) active power of terminal $2 p_{2}$ (blue color) and active power of AC grid $2 p_{g_{2}}$ (red color); (c) active power of terminal $3 p_{3}$ (blue color) and active power of AC grid $3 p_{g_{3}}$ (red color); (d) active power of terminal $4 p_{4}$ (blue color) and active power of AC grid $4 p_{g_{4}}$ (red color).

In addition, Figure 10 also shows, in red color, the active powers extracted (positive value) or absorbed (negative value) from each AC grid: these active powers contain not only the components exchanged with the HVDC system, but also the active power consumed by the various loads connected to the AC grids.

The $d$ and $q$ components of the current injected by each terminal into its AC grid are plotted in blue and red colors, respectively, in Figure 11. Both $d$ and $q$ components contain even harmonics, which are the result of the transformation of the odd harmonics into the SRF. Furthermore, the mean value of the $d$ component of the current is proportional to its respective active power, as shown in Figure 10, while the mean value of the $q$ component of the current is proportional to the RMS value of the voltage at the PCC to which the terminal is connected (see Figure 8 for more details). 

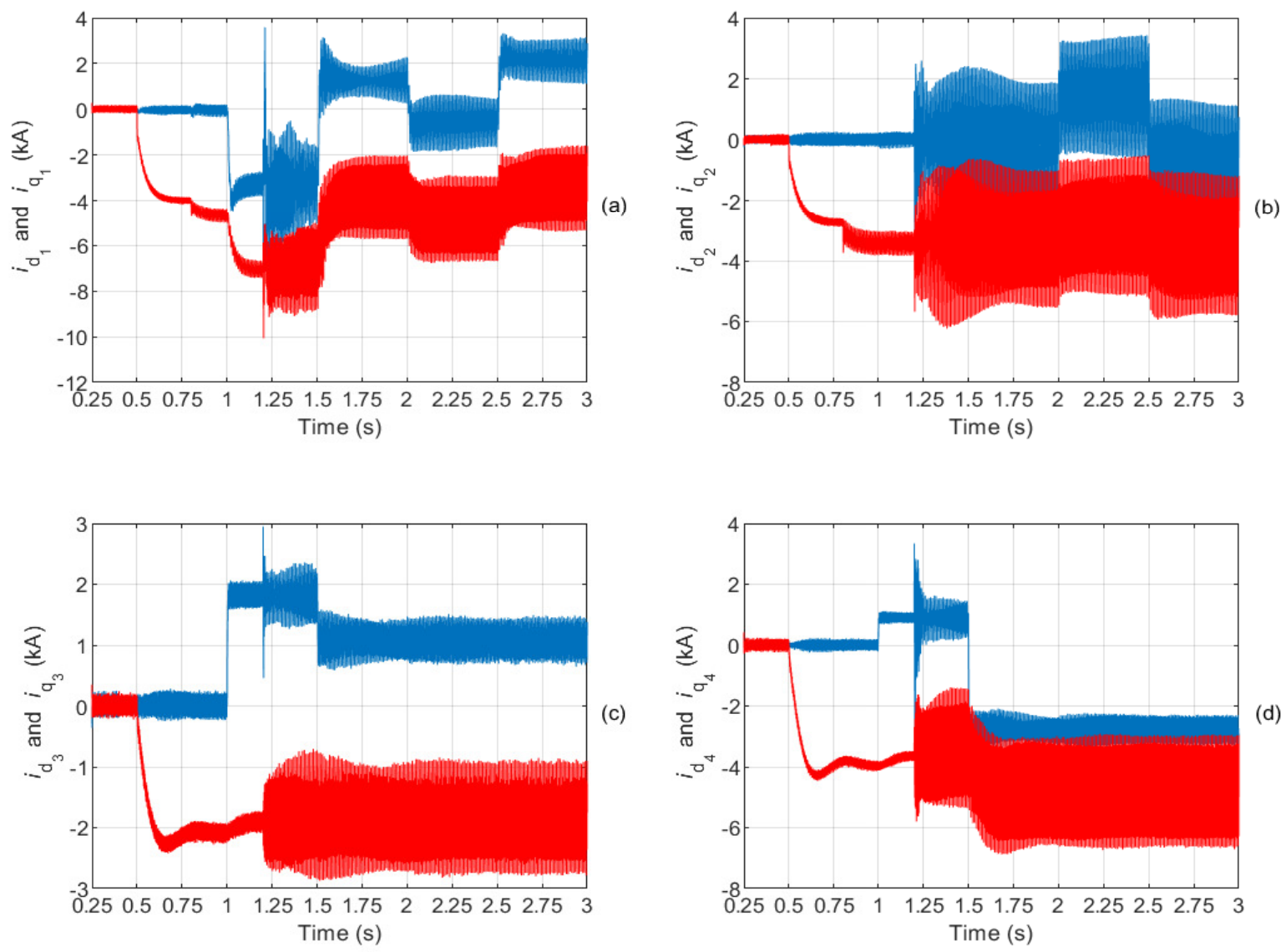

Figure 11. Time responses of the $d$ component (blue color) and $q$ component (red color) of the current through each terminal of the HVDC system: (a) $i_{d_{1}}$ and $i_{q_{1}},(\mathbf{b}) i_{d_{2}}$ and $i_{q_{2}},(\mathbf{c}) i_{d_{3}}$ and $i_{q_{3}}$, and (d) $i_{d_{4}}$ and $i_{q_{4}}$.

Figure 12 show the waveforms obtained from the current through AC grid 1 and the voltage at $\mathrm{PCC}_{1}$ for different time intervals. At instant $t=1.2 \mathrm{~s}$, the resonant regulators $R_{i_{g}}(s)$ are activated; Figure 12a,b show how the grid current and the voltage at $\mathrm{PCC}_{1}$ are unbalanced and contain harmonics before the activation of $R_{i_{g}}(s)$. Once $R_{i_{g}}(s)$ is in operation, the voltage at $\mathrm{PCC}_{1}$ is initially more distorted. At instants $t=1.5 \mathrm{~s}$ and $t=2 \mathrm{~s}$, changes in the active powers of the dispatcher terminal occur, and they cause disturbances in the grid current and the voltage at the PCC that were previously balanced and had low distortion, as shown in Figure 12c-f. Finally, the last change in the active power of terminal 2 occurs at $t=2.5 \mathrm{~s}$, as shown in Figure 12g,h; after this change, the current total harmonic distortion is $T H D_{i}=0.49 \%$, while the voltage total harmonic distortion is $T H D_{v}=1.8 \%$. In the same way, Figures $13-15$ show the waveforms of the current through AC grids 2-4 and the voltages at $\mathrm{PCCs}_{2-4}$ for the same time intervals considered in Figure 12. Similar results are obtained with reduced distortions and balanced current as well as balanced voltages. The values of the total harmonic distortion for the currents and the voltages of the four AC grids are summarized in Table 4 .

Table 4. Total harmonic distortion for the grid current and the voltage at the PCC.

\begin{tabular}{ccccc}
\hline & AC Grid 1 & AC Grid 2 & AC Grid 3 & AC Grid 4 \\
\hline$T H D_{i}(\%)$ & 0.49 & 0.43 & 0.87 & 0.39 \\
\hline$T H D_{v}(\%)$ & 1.8 & 1.7 & 2.1 & 1.9 \\
\hline
\end{tabular}



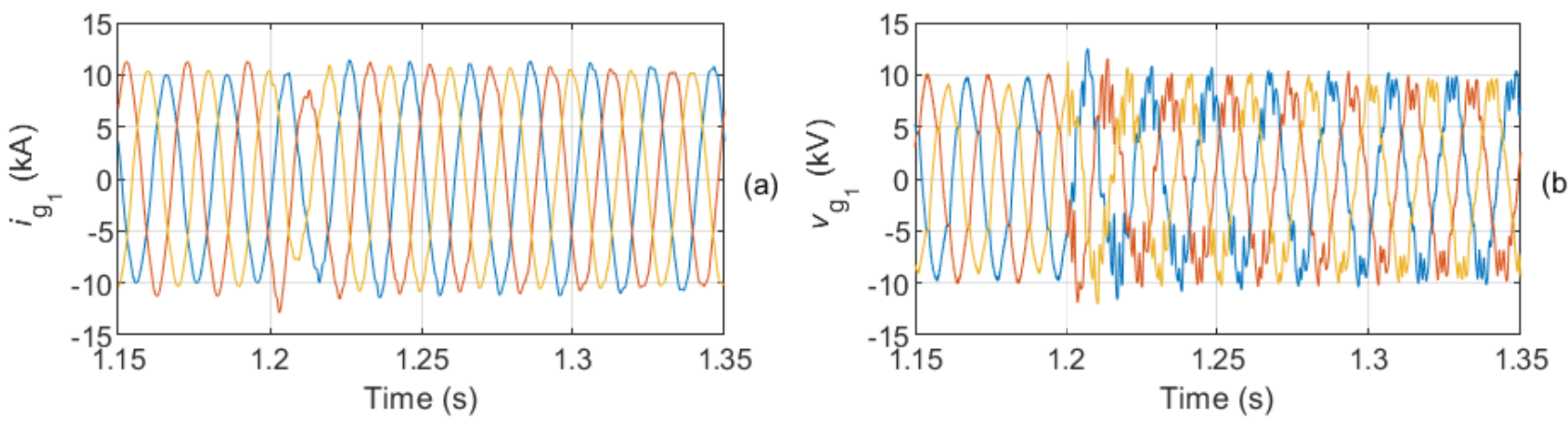

(b)
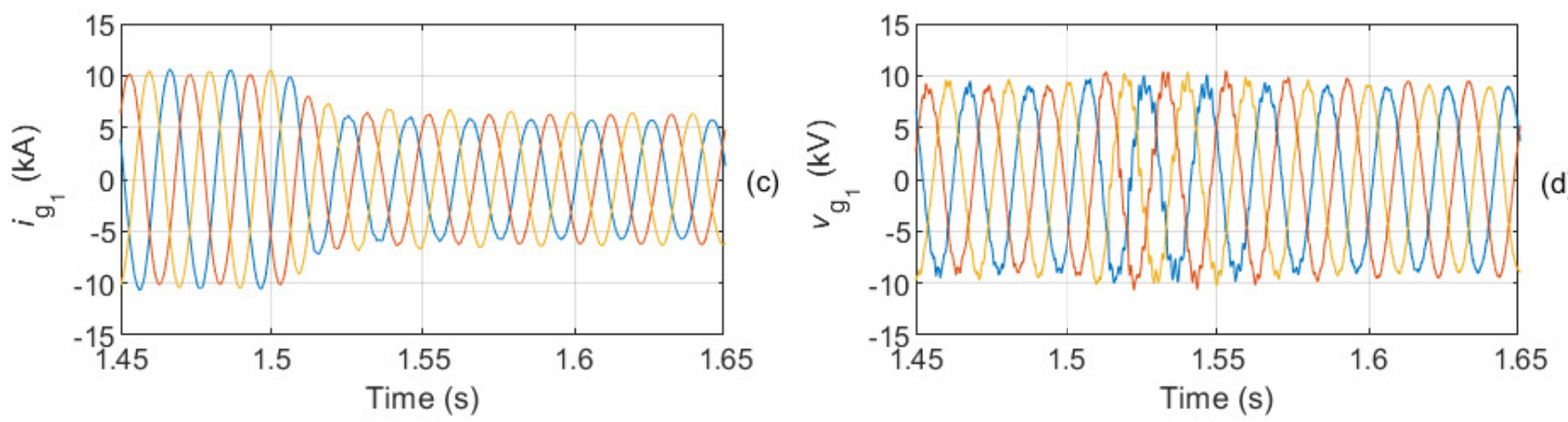

(d)
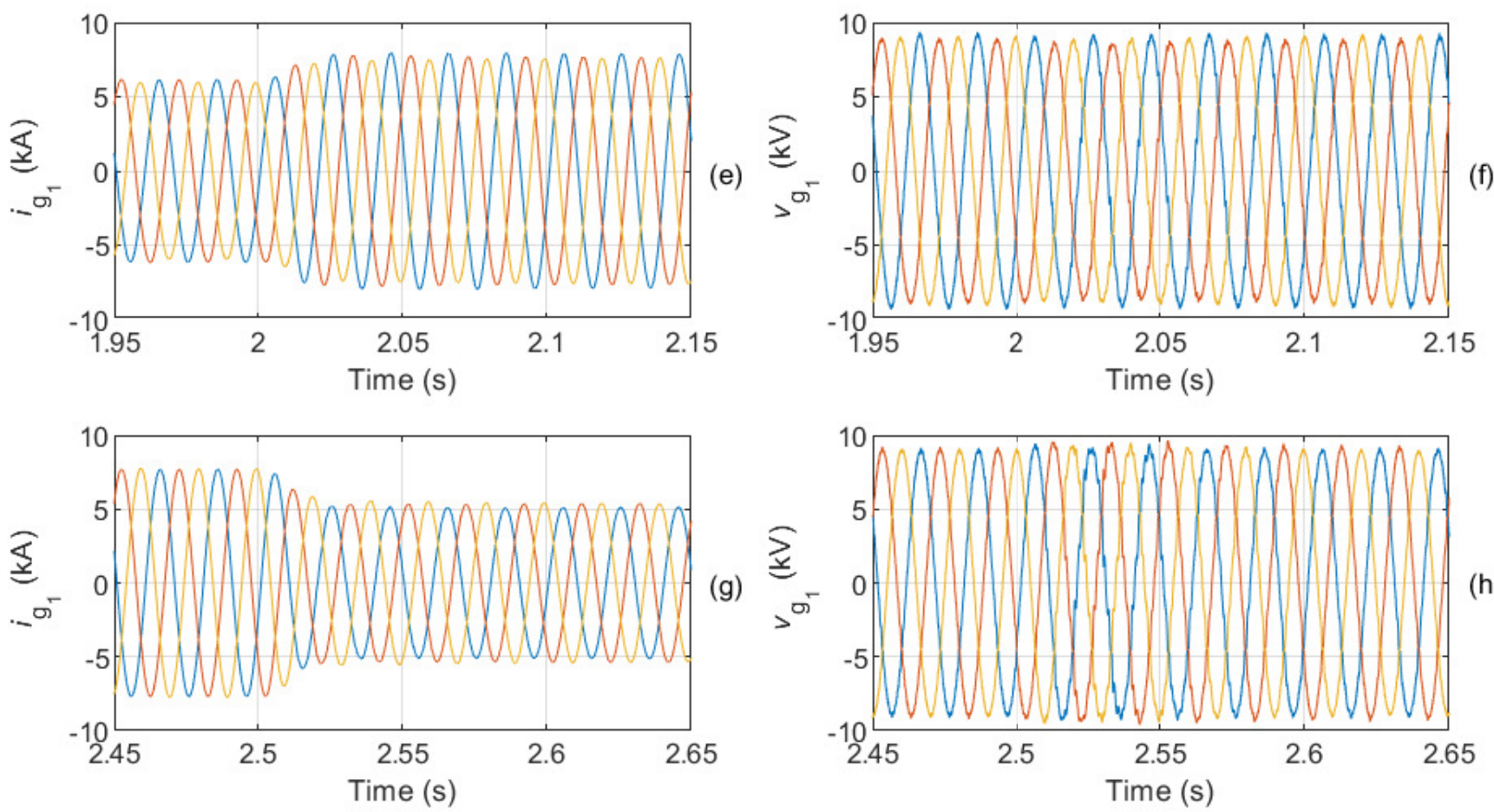

Figure 12. Waveforms obtained from AC grid 1 for different time intervals: (a) grid line currents $(1.15 \mathrm{~s} \leq t \leq 1.35 \mathrm{~s})$, (b) line-to-neutral voltages at $\mathrm{PCC}_{1}(1.15 \mathrm{~s} \leq t \leq 1.35 \mathrm{~s})$, (c) grid line currents $(1.45 \mathrm{~s} \leq t \leq 1.65 \mathrm{~s})$, (d) line-to-neutral voltages at $\mathrm{PCC}_{1}(1.45 \mathrm{~s} \leq t \leq 1.65 \mathrm{~s})$, (e) grid line currents $(1.95 \mathrm{~s} \leq t \leq 2.15 \mathrm{~s})$, (f) line-to-neutral voltages at $\mathrm{PCC}_{1}$ $(1.95 \mathrm{~s} \leq t \leq 2.15 \mathrm{~s}),(\mathrm{g})$ grid line currents $(2.45 \mathrm{~s} \leq t \leq 2.65 \mathrm{~s})$, and (h) line-to-neutral voltages at PCC $_{1}(2.45 \mathrm{~s} \leq t \leq 2.65 \mathrm{~s})$. 

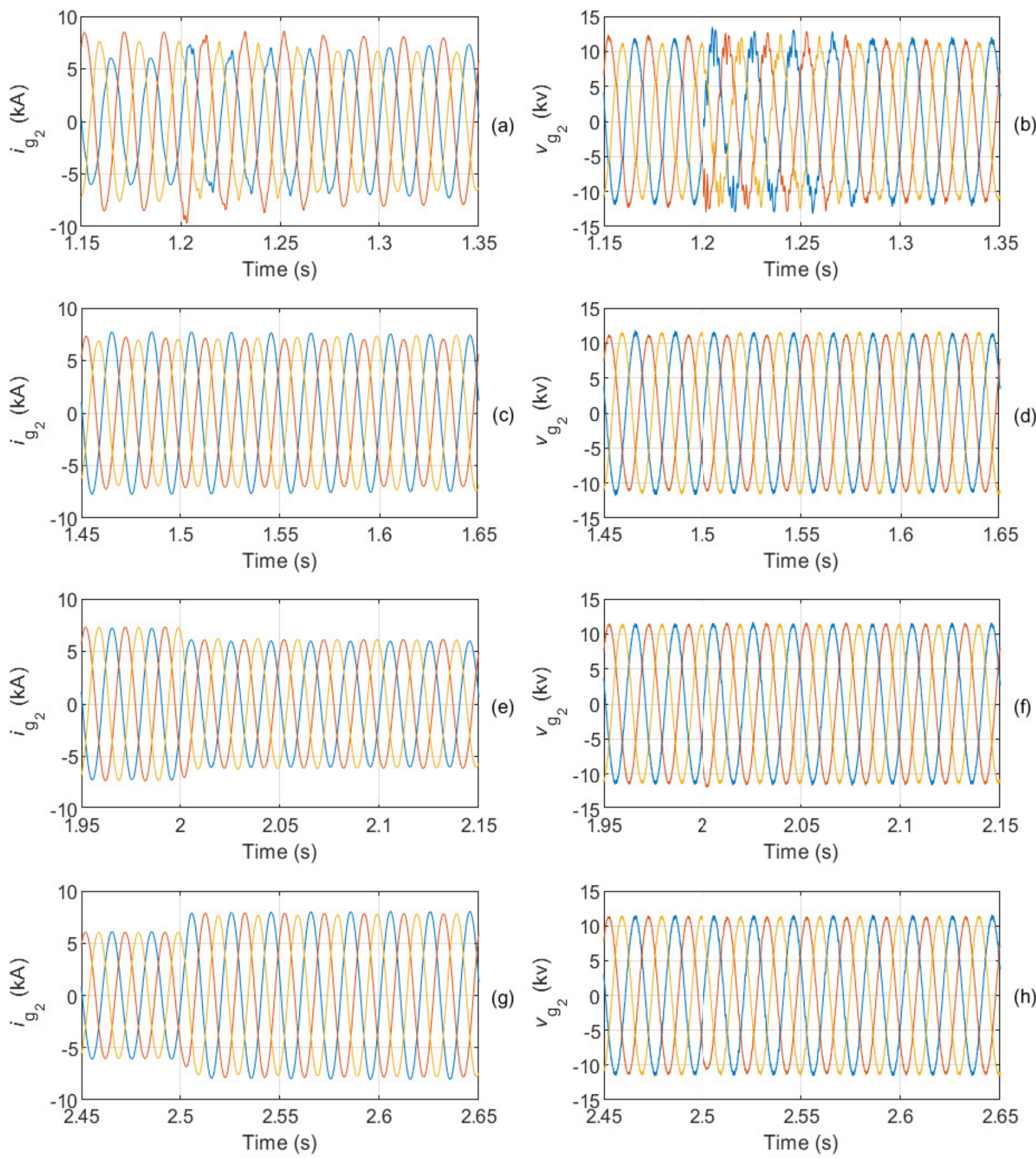

Figure 13. Waveforms obtained from AC grid 2 for different time intervals: (a) grid line currents (1.15 s $\leq t \leq 1.35 \mathrm{~s})$, (b) line-to-neutral voltages at $\mathrm{PCC}_{2}(1.15 \mathrm{~s} \leq t \leq 1.35 \mathrm{~s})$, (c) grid line currents $(1.45 \mathrm{~s} \leq t \leq 1.65 \mathrm{~s})$, (d) line-to-neutral voltages at $\mathrm{PCC}_{2}(1.45 \mathrm{~s} \leq t \leq 1.65 \mathrm{~s})$, (e) grid line currents $(1.95 \mathrm{~s} \leq t \leq 2.15 \mathrm{~s})$, (f) line-to-neutral voltages at $\mathrm{PCC}_{2}$ $(1.95 \mathrm{~s} \leq t \leq 2.15 \mathrm{~s}),(\mathrm{g})$ grid line currents $(2.45 \mathrm{~s} \leq t \leq 2.65 \mathrm{~s})$, and (h) line-to-neutral voltages at PCC $_{2}(2.45 \mathrm{~s} \leq t \leq 2.65 \mathrm{~s})$. 

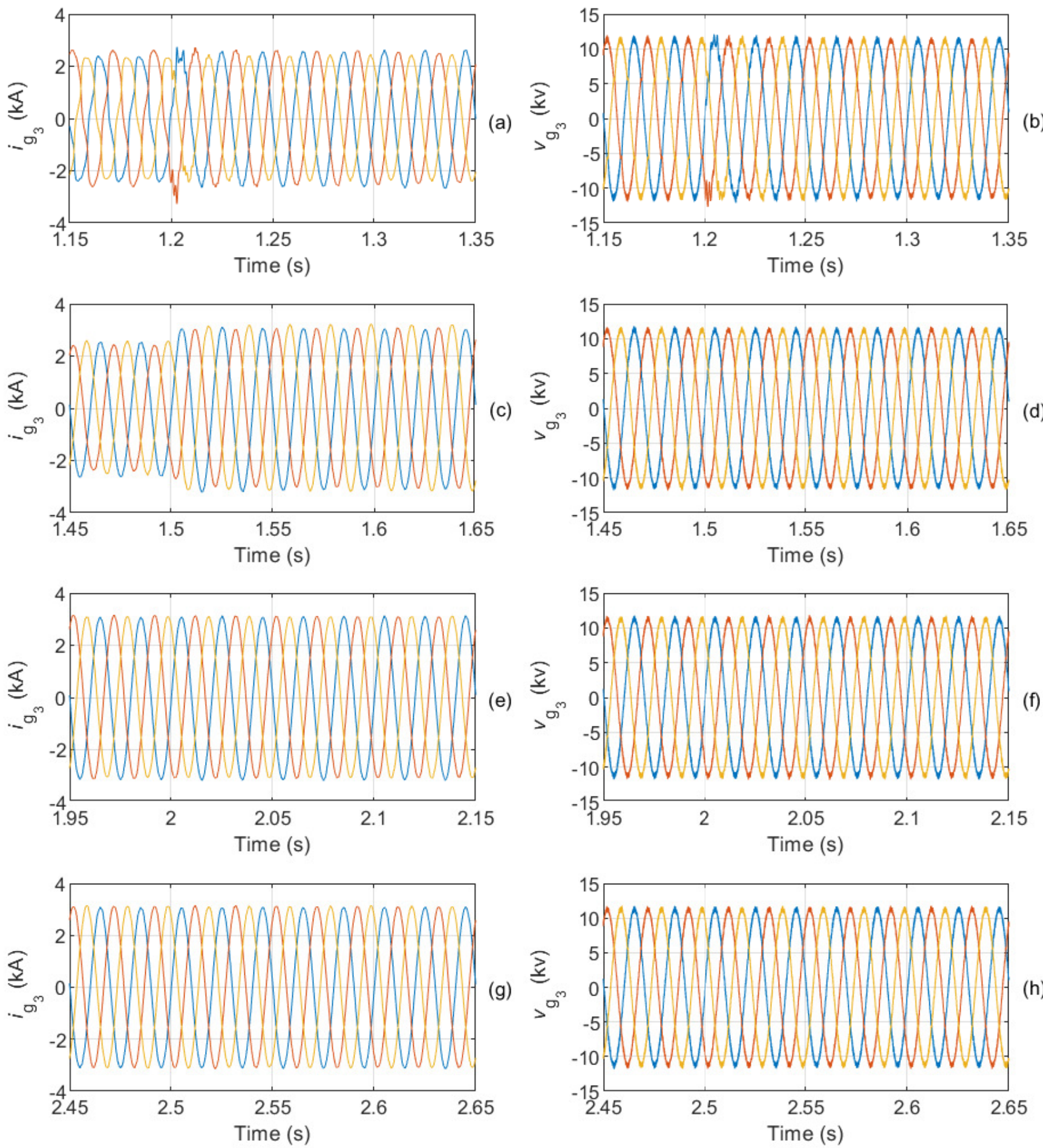

Figure 14. Waveforms obtained from AC grid 3 for different time intervals: (a) grid line currents $(1.15 \mathrm{~s} \leq t \leq 1.35 \mathrm{~s})$, (b) line-to-neutral voltages at $\mathrm{PCC}_{3}(1.15 \mathrm{~s} \leq t \leq 1.35 \mathrm{~s})$, (c) grid line currents $(1.45 \mathrm{~s} \leq t \leq 1.65 \mathrm{~s})$, (d) line-to-neutral voltages at $\mathrm{PCC}_{3}(1.45 \mathrm{~s} \leq t \leq 1.65 \mathrm{~s})$, (e) grid line currents $(1.95 \mathrm{~s} \leq t \leq 2.15 \mathrm{~s})$, (f) line-to-neutral voltages at $\mathrm{PCC}_{3}$ $(1.95 \mathrm{~s} \leq t \leq 2.15 \mathrm{~s}),(\mathrm{g})$ grid line currents $(2.45 \mathrm{~s} \leq t \leq 2.65 \mathrm{~s})$, and (h) line-to-neutral voltages at $\mathrm{PCC}_{3}(2.45 \mathrm{~s} \leq t \leq 2.65 \mathrm{~s})$. 

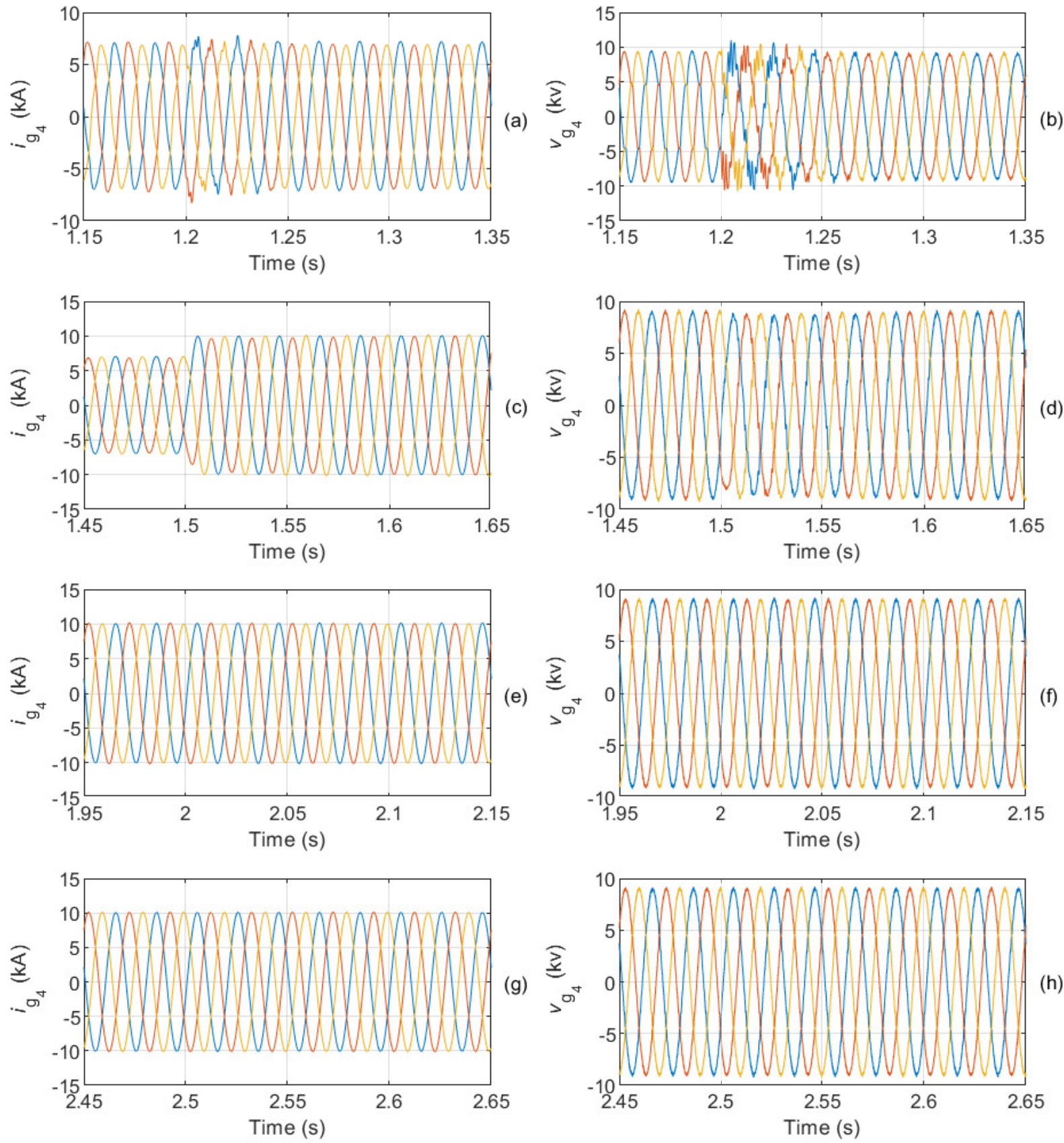

Figure 15. Waveforms obtained from AC grid 4 for different time intervals: (a) grid line currents (1.15 s $\leq t \leq 1.35 \mathrm{~s})$, (b) line-to-neutral voltages at $\mathrm{PCC}_{4}(1.15 \mathrm{~s} \leq t \leq 1.35 \mathrm{~s})$, (c) grid line currents $(1.45 \mathrm{~s} \leq t \leq 1.65 \mathrm{~s})$, (d) line-to-neutral voltages at $\mathrm{PCC}_{4}(1.45 \mathrm{~s} \leq t \leq 1.65 \mathrm{~s})$, (e) grid line currents $(1.95 \mathrm{~s} \leq t \leq 2.15 \mathrm{~s})$, (f) line-to-neutral voltages at $\mathrm{PCC}_{4}$ $(1.95 \mathrm{~s} \leq t \leq 2.15 \mathrm{~s}),(\mathrm{g})$ grid line currents $(2.45 \mathrm{~s} \leq t \leq 2.65 \mathrm{~s})$, and (h) line-to-neutral voltages at PCC $_{4}(2.45 \mathrm{~s} \leq t \leq 2.65 \mathrm{~s})$.

\section{Conclusions}

In this paper, a four-terminal HVDC system is presented that is able to improve the $\mathrm{PQ}$ of the AC grids to which it is connected. This HVDC scheme employs four three-phase three-level NPC VSCs in order to obtain an output voltage with low harmonic content. A control scheme is in charge of compensating for the active power between the various AC grids and to cancel out voltage sags and voltage imbalances in the PCC. In order to achieve these goals, the control topology contains several PI regulators together with resonant controllers, all of them implemented in the SRF. The structure of the regulators allows us to design the parameters of each controller transfer function independently. The results 
obtained in the proposed case study show that the HVDC system is able to maintain the voltage across the $\mathrm{DC}$ bus while controlling the power active flow between the AC grids. Moreover, the compensation of imbalances, sags, and harmonics in the grid voltages is also effective, showing a robust response against the connection of several linear and nonlinear loads, even in the presence of imbalances. Thus, the simulation results show a satisfactory performance of the overall control system with zero-error tracking in the steady-state and an appropriate transient response with very reduced values for the total harmonic distortions of both voltage and current. The results also demonstrate that the proposed control scheme applied to an HVDC system with four terminals is able to deal successfully with the main voltage quality disturbances present in the AC grids. An increase in the number of terminals is not expected to significantly alter the system response, since the control system of a given terminal can be tailored independently, exerting a reduced influence over the others. This work demonstrates, therefore, that the capabilities of HVDC systems for improving the PQ of AC grids can be exploited to contribute to developing more reliable power grids. Among these capabilities, the cancellation of harmonics and imbalances when the grid frequency undergoes small changes should be investigated in control schemes based on the use of resonant controllers.

Author Contributions: Conceptualization, P.R.-S. and A.P.T.; methodology, P.R.-S. and J.V.; software, E.J.M.-M. and F.J.L.-A.; validation, E.J.M.-M., F.J.L.-A., and F.G.-T.; formal analysis, P.R.-S. and A.P.T.; investigation, P.R.-S. and F.J.L.-A.; resources, P.R.-S. and J.V.; data curation, E.J.M.-M. and F.J.L.-A.; writing-original draft preparation, P.R.-S. and A.P.T.; writing—review and editing, J.V., F.J.L.-A. and F.G.-T.; visualization, All authors; supervision, P.R.-S. and J.V.; project administration, P.R.-S.; funding acquisition, P.R.-S., J.V., and F.G.-T. All authors have read and agreed to the published version of the manuscript.

Funding: This research was funded by European Regional Development Fund (ERDF) under the program Interreg SUDOE SOE3/P3/E0901 (Project IMPROVEMENT).

Conflicts of Interest: The authors declare no conflict of interest. The funders had no role in the design of the study; in the collection, analyses, or interpretation of data; in the writing of the manuscript, or in the decision to publish the results.

\begin{tabular}{|c|c|}
\hline \multicolumn{2}{|c|}{ Abbreviations } \\
\hline \multicolumn{2}{|c|}{ The following abbreviations are used in this manuscript: } \\
\hline HVDC & High Voltage Direct Current \\
\hline VSC & Voltage Source Converter \\
\hline CSC & Current Source Converter \\
\hline PCC & Point of Common Coupling \\
\hline PQ & Power Quality \\
\hline PI & Proportional-Integral \\
\hline DC & Direct Current \\
\hline $\mathrm{AC}$ & Alternating Current \\
\hline HVAC & High-Voltage Alternating Current \\
\hline NPC & Neutral-Point Clamped \\
\hline FC & Flying Capacitor \\
\hline MMC & Modular Multilevel Converter \\
\hline FTS & Flexible Transmission Systems \\
\hline SRF & Synchronous Reference Frame \\
\hline THD & Total Harmonic Distortion \\
\hline Brk & Breaker \\
\hline SPWM & Sinusoidal Pulse-Width Modulation \\
\hline RMS & Root-Mean Square \\
\hline PR & Proportional Resonant \\
\hline IGBT & Insulated-Gate Bipolar Transistor \\
\hline PSCAD & Power System Computer-Aided Design \\
\hline EMTDC & Electromagnetic Transients including Direct $\mathrm{C}$ \\
\hline
\end{tabular}




\section{References}

1. Li, Y.; Tang, G.; An, T.; Pang, H.; Wang, P.; Yang, J.; Wu, Y.; He, Z. Power Compensation Control for Interconnection of Weak Power Systems by VSC-HVDC. IEEE Trans. Power Deliv. 2017, 32, 1964-1974. [CrossRef]

2. Watson, N.R.; Watson, J.D. An Overview of HVDC Technology. Energies 2020, 13, 4342. [CrossRef]

3. Ekanayake, J.B.; Jenkins, N.; Liyanage, K.; Wu, J.; Yokoyama, A. Smart Grid: Technology and Applications; John Wiley \& Sons: Chichester, UK, 2012.

4. Ashabani, M.; Mohamed, Y.A.I. Novel Comprehensive Control Framework for Incorporating VSCs to Smart Power Grids Using Bidirectional Synchronous-VSC. IEEE Trans. Power Syst. 2014, 29, 943-957. [CrossRef]

5. Jacobson, B.; Jiang-Härner, Y.; Rey, P.; Asplund, G.; Jeroense, M.; Gustafsson, A.; Bergkvist, M. HVDC with Voltage Source Converters and Extruded Cables for up to $+/-300 \mathrm{kV}$ and $1000 \mathrm{MW}$; Cigre Session: Paris, France, 2006.

6. Okba, M.H.; Saied, M.H.; Mostafa, M.Z.; Abdel-Moneim, T.M. High voltage direct current transmission-A Review, Part II-Converter technologies. In Proceedings of the 2012 IEEE Energytech, Cleveland, OH, USA, 29-31 May 2012 ; pp. 1-7.

7. Acha, E.; Roncero-Sánchez, P.; de la Villa-Jaén, A.; Castro, L.M.; Kazemtabrizi, B. VSC-FACTS-HVDC: Analysis, Modelling and Simulation in Power Grids; John Wiley \& Sons: Chichester, UK, 2019.

8. Wang, F.; Bertling, L.; Le, T.; Mannikoff, A.; Bergman, A. An Overview Introduction of VSC-HVDC: State-of-art and Potential Applications in Electric Power Systems. In Proceedings of the Cigrè International Symposium, Bologna, Italy, 13-15 September 2011; pp. 1-10.

9. Álvarez Romero, G.; Castro, L.M.; Roncero-Sánchez, P. Effective sensitivity-based method for N-1 contingency analysis of VSC-based MTDC power grids considering power generation droop speed controls. Int. J. Electr. Power Energy Syst. 2020, 122, 106175. [CrossRef]

10. Rodríguez, J.; Lai, J.-S.; Peng, F.Z. Multilevel inverters: A survey of topologies, controls, and applications. IEEE Trans. Ind. Electron. 2002, 49, 724-738.

11. Roncero-Sánchez, P.; Acha, E. Dynamic Voltage Restorer Based on Flying Capacitor Multilevel Converters Operated by Repetitive Control. IEEE Trans. Power Deliv. 2009, 24, 951-960. [CrossRef]

12. Ding, G.; Tang, G.; He, Z.; Ding, M. New technologies of voltage source converter (VSC) for HVDC transmission system based on VSC. In Proceedings of the 2008 IEEE Power and Energy Society General Meeting-Conversion and Delivery of Electrical Energy in the 21st Century, Pittsburgh, PA, USA, 20-24 July 2008; pp. 1-8.

13. Gandoman, F.H.; Ahmadi, A.; Sharaf, A.M.; Siano, P.; Pou, J.; Hredzak, B.; Agelidis, V.G. Review of FACTS technologies and applications for power quality in smart grids with renewable energy systems. Renew. Sustain. Energy Rev. 2018, 82, 502-514. [CrossRef]

14. Kim, H.; Kim, S.; Chung, Y.; Yoo, D.; Kim, C.; Hur, K. Operating Region of Modular Multilevel Converter for HVDC With Controlled Second-Order Harmonic Circulating Current: Elaborating P-Q Capability. IEEE Trans. Power Deliv. 2016, 31, 493-502. [CrossRef]

15. Chen, H.; Zhang, F.; Chang, Y. Improvement of power quality by VSC based multi-terminal HVDC. In Proceedings of the 2006 IEEE Power Engineering Society General Meeting, Montreal, QC, Canada, 18-22 June 2006; pp. 1-6.

16. Antar, R.K.; Saied, B.M.; Khalil, R.A.; Putrus, G.A. HVDC link power quality improvement using a modified active power filter. In Proceedings of the 2012 47th International Universities Power Engineering Conference (UPEC), Uxbridge, UK, 4-7 September 2012; pp. 1-5.

17. Zangana, S.; Ercelebi, E. Enhance Power Quality by HVDC System, Comparison Technique between HVDC and HVAC Transmission Systems. Int. J. Comput. Syst. Eng. 2016, 10, 271-279.

18. Liu, W.; Zheng, T.; Liu, Z.; Fan, Z.; Kang, Y.; Wang, D.; Zhang, M.; Miao, S. Active and Reactive Power Compensation Control Strategy for VSC-HVDC Systems under Unbalanced Grid Conditions. Energies 2018, 11, 3140. [CrossRef]

19. Luo, A.; Xu, Q.; Ma, F.; Chen, Y. Overview of power quality analysis and control technology for the smart grid. J. Mod. Power Syst. Clean Energy 2016, 4, 1-9. [CrossRef]

20. Arrillaga, J.; Liu, Y.H.; Watson, R.N. Flexible Power Transmission. The HVDC Options; John Wiley \& Sons: Chichester, UK, 2007.

21. Soto, D.; Green, T.C. A comparison of high-power converter topologies for the implementation of FACTS controllers. IEEE Trans. Ind. Electron. 2002, 49, 1072-1080. [CrossRef]

22. Kundur, P. Power System Stability and Control; McGraw-Hill, Inc.: New York, NY, USA, 1994.

23. Guan, M.; Cheng, J.; Wang, C.; Hao, Q.; Pan, W.; Zhang, J.; Zheng, X. The Frequency Regulation Scheme of Interconnected Grids With VSC-HVDC Links. IEEE Trans. Power Syst. 2017, 32, 864-872. [CrossRef]

24. Roncero-Sánchez, P.; Torres, A.P.; Vázquez, J. Control scheme of a concentration photovoltaic plant with a hybrid energy storage system connected to the grid. Energies 2018, 11, 301. [CrossRef]

25. Roncero-Sánchez, P.; Acha, E. Design of a Control Scheme for Distribution Static Synchronous Compensators with Power-Quality Improvement Capability. Energies 2014, 7, 2476-2497. [CrossRef]

26. Yazdani, A.; Iravani, R. Voltage-Sourced Converters in Power Systems: Modeling, Control, and Applications; Wiley-IEEE Press: Hoboken, NJ, USA, 2010.

27. Roncero-Sánchez, P.; del Toro Garcia, X.; Torres, A.P.; Feliu, V. Fundamental Positive- and Negative-Sequence Estimator for Grid Synchronization Under Highly Disturbed Operating Conditions. IEEE Trans. Power Electron. 2013, 28, 3733-3746. [CrossRef]

28. Hart, D.W. Power Electronics, International ed.; McGraw-Hill: New York, NY, USA, 2011. 
29. Li, Y.W.; Loh, P.C.; Blaabjerg, F.; Vilathgamuwa, D.M. Investigation and Improvement of Transient Response of DVR at Medium Voltage Level. IEEE Trans. Ind. Appl. 2007, 43, 1309-1319. [CrossRef]

30. Gonzalez-Espin, F.; Figueres, E.; Garcera, G. An Adaptive Synchronous-Reference-Frame Phase-Locked Loop for Power Quality Improvement in a Polluted Utility Grid. IEEE Trans. Ind. Electron. 2012, 59, 2718-2731. [CrossRef]

31. Roncero-Sánchez, P.; Acha, E. Harmonic and imbalance voltage mitigation in smart grids: A DSTATCOM based solution. In Proceedings of the IEEE EUROCON 2015-International Conference on Computer as a Tool (EUROCON), Salamanca, Spain, 8-11 September 2015; pp. 1-6.

32. Mattavelli, P. Synchronous-frame harmonic control for high-performance AC power supplies. IEEE Trans. Ind. Appl. 2001, 37, 864-872. [CrossRef]

33. Mohan, N.; Undeland, T.M.; Robbins, W.P. Power Electronics: Converters, Applications and Design, 3rd ed.; Wiley-IEEE Press: Hoboken, NJ, USA, 2002.

34. Ogata, K. Modern Control Engineering, 5th ed.; Pearson Education, Inc.: Bergen, NJ, USA, 2010.

35. Nise, N.S. Control Systems Engineering, 6th ed.; Wiley: Somerset, NJ, USA, 2011. 